\title{
8-1-1971
}

\section{Interstimulus Intervals in Conditioned Suppression}

John Oliver Kling

How does access to this work benefit you? Let us know!

Follow this and additional works at: https://commons.und.edu/theses

\section{Recommended Citation}

Kling, John Oliver, "Interstimulus Intervals in Conditioned Suppression" (1971). Theses and Dissertations. 3500.

https://commons.und.edu/theses/3500

This Dissertation is brought to you for free and open access by the Theses, Dissertations, and Senior Projects at UND Scholarly Commons. It has been accepted for inclusion in Theses and Dissertations by an authorized administrator of UND Scholarly Commons. For more information, please contact und.commons@library.und.edu. 
INTERSTIMULUS INTERVALS IN CONDITIONED SUPPRESSION

by

John Oliver Kling

Bachelor of Arts, University of Minnesota 1967

Master of Arts, University of North Dakota 1970

\author{
A Dissertation \\ Submitted to the Faculty \\ of the \\ University of North Dakota \\ in partial fulfillment of the requirements \\ for the degree of \\ Doctor of Philosophy
}

Grand Forks, North Dakota

August

1971 
This dissertation submitted by John Oliver Kling in partial fulfillment of the requirements for the Degree of Doctor of Philosophy from the University of North Dakota is hereby approved by the Faculty Advisory Committee under whom the work has been done.
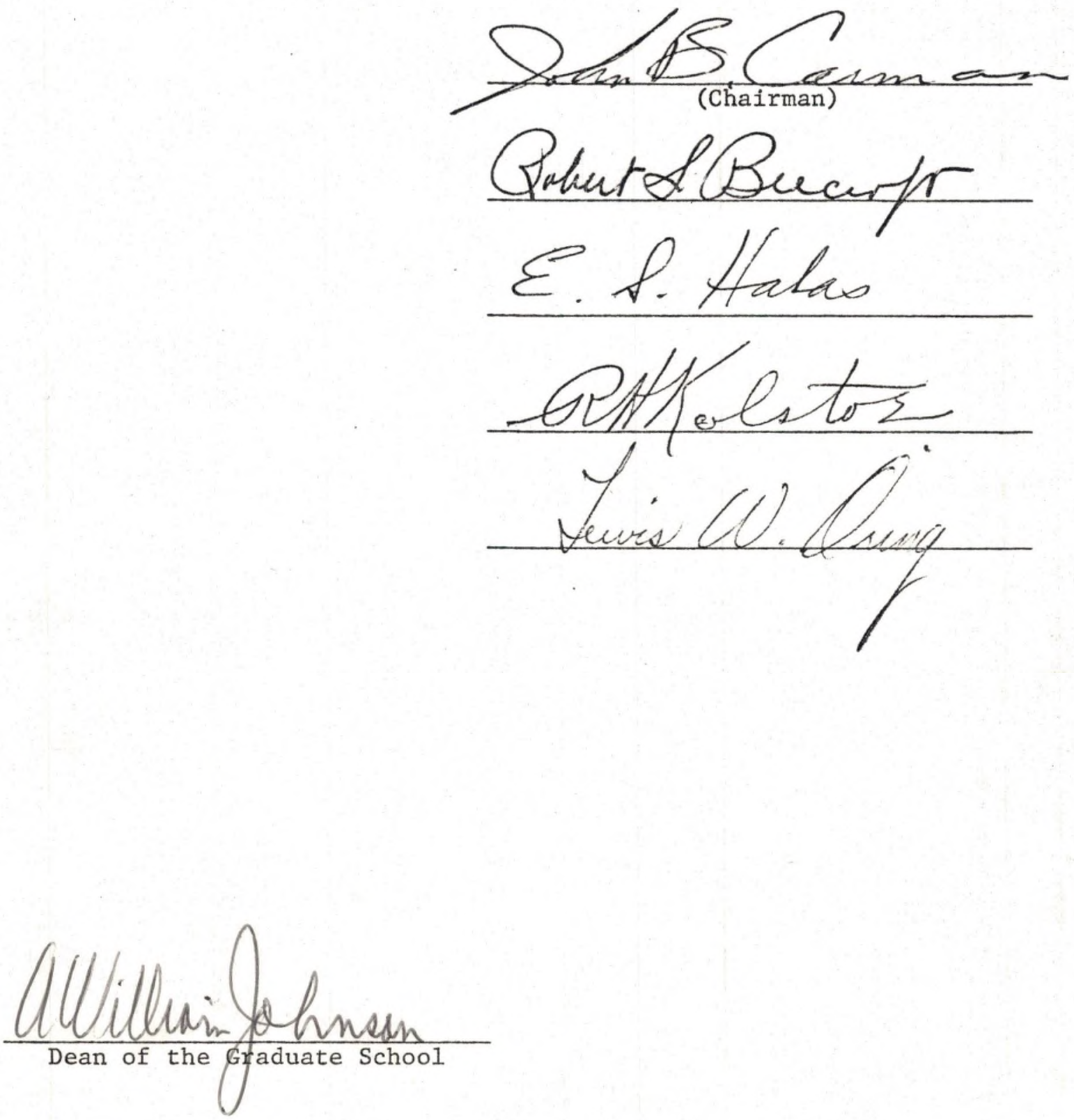
Permission

Title INTERSTIMULUS INTERVALS IN CONDITIONED SUPPRESSION

Department

Psychology

Degree Doctor of Philosophy

In presenting this dissertation in partial fulfillment of the requirements for a graduate degree from the University of North Dakota, I agree that the Library of this University shall make it freely available for inspection. I further agree that permission for extensive copying for scholarly purposes may be granted by the professor who supervised my dissertation work or, in his absence, by the Chairman of the Department or the Dean of the Graduate School. It is understood that any copying or publication or other use of this dissertation or part thereof for financial gain shall not be allowed without my written permission. It is also understood that due recognition shall be given to me and to the University of North Dakota in any scholarly use which may be made of any material in my dissertation.
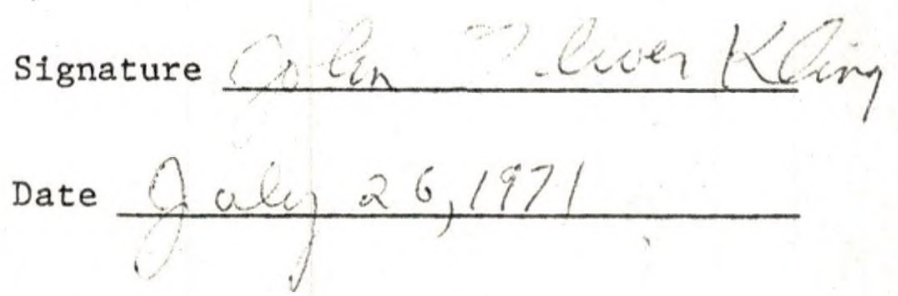


\section{ACKNOWLEDGMENTS}

I would like to express my appreciation to Dr. John B. Carman, Dr. Robert S. Beecroft, Dr. Ralph H. Kolstoe, Dr. Edward S. Halas, and Dr. Lewis Oring for their assistance. I wish to thank Dr. Beecroft for his assistance with the statistical analysis. I am especially indebted to $\mathrm{Dr}$. Carman for making the necessary equipment avallable for my use and for helping in the writing of this dissertation.

Finally, I would like to thank Kathleen Kling, Dick Harder, Richard Metzger, and S. Richard Gunn for providing helpful suggestions in the writing of this dissertation. 
TABLE OF CONTENTS

Page

ACKNOWLEDGMENTS . . . . . . . . . . . . . . . . . . Iv

LIST OF TABLES . . . . . . . . . . . . . . . . . . v1

LIST OF FIGURES . . . . . . . . . . . . . . . . . vil

ABSTRACT ......................... . . . 1 . . . . . .

Chapter

I. INTRODUCTION AND REVIEW OF THE LITERATURE . . . . . . . . 1

UCS Intensity

CS Intensity

CS-UCS Interval

Partial Reinforcement

Stimulus Generalization

Differential and Higher Order Conditioning

Reinforcement Baseline

Statement of the Problem

II. METHOD .........................

Subjects

Apparatus

Procedure

III. RESULTS . . . . . . . . . . . . . . . . 26

IV. DISCUSSION .................... 56

APPENDIX A . . . . . . . . . . . . . . . . . . . . . 66

APPENDIX B . . . . . . . . . . . . . . . . . . 68

APPENDIX C . . . . . . . . . . . . . . . . . 77

REFERENCES . . . . . . . . . . . . . . . . . . . . 80 
LIST OF TABLES

Table

Page

1. Means and Standard Deviations: Habituation

Suppression Ratios........ . . . . . . . . .

2. Analysis of Variance: Habituation Suppression

Ratios . . . . . . . . . . . . . . . . .

3. Means and Standard Deviations: Acquisition of Suppression Ratios... . . . . . . . . . . . . 44

4. Analysis of Variance: Acquisition of Suppression

Ratios . . . . . . . . . . . . . . . . 44

5. Means and Standard Deviations of Suppression Ratios:

3-Second Test Group . . . . . . . . . . . . . .

6. Analysis of Variance of Suppression Ratios: 3-Second

Test Group . . . . . . . . . . . . . . . . . . .

7. Means and Standard Deviations of Suppression Ratios:

30-Second Test Group . . . . . . . . . . . . . .

8. Analysis of Variance of Suppression Ratios: 30-Second

Test Group . . . . . . . . . . . . . . . . . . . .

9. Means and Standard Deviations: Extinction of

Suppression Ratios . . . . . . . . . . . . . . .

10. Analysis of Variance: Extinction of Suppression

Ratios . . . . . . . . . . . . . . . . . . .

11. Suppression Ratios for Each Subject for Habituation

Days . . . . . . . . . . . . . . . . . .

12. Suppression Ratios for Each Group for Acquisition and Extinction 


\section{LIST OF FIGURES}

Figure

Page

1. Suppression Ratios for Group 1, 1-Second Training 3-Second Test. . . . . . . . . . . . . . .

2. Suppression Ratios for Group 2, 3-Second Training 3-Second Test....................

3. Suppression Ratios for Group 3, 7-Second Training 3-Second Test . . . . . . . . . . . . . . . .

4. Suppression Ratios for Group 4, 30-Second Training 3-Second Test.

5. Suppression Ratios for Group 5, 1-Second Training 30-Second Test

6. Suppression Ratios for Group 6, 3-Second Training 30-Second Test

7. Suppression Ratios for Group 7, 7-Second Training 30-Second Tes

8. Suppression Ratios for Group 8, 30-Second Training 30-Second Test

9. Suppression Ratios for the 3-Second Test Group . . . . . . 48

10. Suppression Ratios for the 30-Second Test Group . . . . . .

11. Suppression Ratios Across CS-UCS Intervals for 3- and 30-Second Groups . . . . . . . . . . . .

12. Suppression Ratios Across CS-UCS Intervals for the 3- and 30-Second Test Groups on Day 1. . . . . .

13. Suppression Ratios Across CS-UCS Intervals for the 3- and 30-Second Test Groups on Day 2 . . . . . . .

14. Suppression Ratios Across CS-UCS Intervals for the 3- and 30-Second Test Groups on Day 3 . . . . . .

15. Suppression Ratios Across CS-UCS Intervals for the 3- and 30-Second Test Groups on Day 4. . . . . . . 
16. Suppression Ratios Across CS-UCS Intervals for the 3- and 30-Second Test Groups on Day 5 . . . . . . . 53

17. Suppression Ratios for Training and Testing by Trials $\left(C_{1}\right)$. . . . . . . . . . . . . . 79

18. Suppression Ratios for Training and Testing by Trials $\left(\mathrm{C}_{2}\right)$. . . . . . . . . . . . 79

19. Suppression Ratios for Training and Testing by Trials $\left(\mathrm{C}_{3}\right)$. . . . . . . . . . . . . 79

20. Suppression Ratios for Training and Testing by

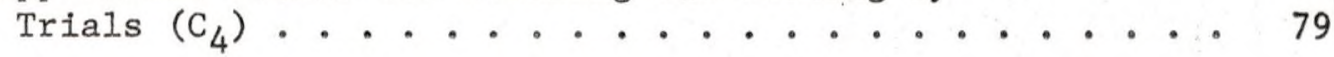




\section{ABSTRACT}

Conditioned suppression describes the attenuation of an ongoing operant (e.g., lever press or key peck) when a warning stimulus precedes unavoidable electric shock. First reported by Estes and Skinner (1941), the procedure has been refined by Kamin (1961, 1965) and other investigators (Geller, 1963, 1964; Hunt and Brady, 1955; and James and Mostoway, 1968). Although many of the parameters of conditioned suppression have been evaluated, relatively little attention has been given to interstimulus intervals. In the only parametric study of interstimulus intervals, Libby (1951) investigated seven short intervals ranging from 0 to 30 seconds. He reported that suppression increased as the interstimulus interval increased from 0 to 10 seconds and showed a slight decrease from 10 to 30 seconds.

Using a modification of the Estes and Skinner (1941) procedure, the present study replicated that of Libby (1951). The present investigation employed a consummatory lick response as an operant. Since the lick response is emitted at a higher rate than is the bar press response, this procedure permitted a more reliable assessment of the effect of interstimulus intervals upon acquisition of conditioned suppression. Thirty-two Sprague-Dawley rats were randomly assigned to one of eight groups differing in the interstimulus interval at which they were trained (1-, 3-, 7-, and 30-seconds) and tested (3- and 30seconds). Following habituation to the $1000 \mathrm{~Hz}$ tone CS, Ss received 
one training trial and one test trial daily for 16 sessions. During extinction all Ss recelved two 30-second test trials with UCS omitted. Extinction was continued until each $S^{\prime}$ s responding had recovered to the pre-suppression training level. No significant differences in either acquisition. or extinction were found between the various interstimulus Interva1s. However, certain regularities in the data suggest that the 3- and 7-second interstimulus intervals produce greater suppression. Although this differs from Libby's (1951) finding of increased suppression up to 10 seconds, the intervals at which conditioning is best in both studies is within the range suggested from classical heart and lick conditioning studies. Several explanations for failure to replicate Libby's (1951) results were offered. These explanations involved analysis of the different methodologies employed in the two studies. 
CHAPTER I

\section{INTRODUCTION AND REVIEW OF THE LITERATURE}

The construct of anxiety is central to the understanding of behavior in the twentieth century.

The seventeenth century has been called the Age of Enlightment; the eighteenth century, the Age of Reason; the nineteenth, the Age of Progress; and the twentieth, the Age of Anxiety. With the conquest of many of the physical ills which have affected him throughout his history, man has become increasingly aware of the role of psychological factors in human existence. No longer are civilized men--at least the fortunate majority--the victims of famines and epidemics. The black plague has been replaced by a host of subtler psychological plagues--worry, value conflicts, loneliness, disillusionment, and doubts as to whether one can weave a successful course through the complex maze of freeways and blind alleys that make up modern existence (Coleman, 1964, p. 2).

Anxiety is the most common of the psychoneurotic reaction patterns, constituting 30 to 40 per cent of al1 neurotic disorders (Coleman, 1964). The reaction pattern consists of a relative constant state of tension, restlessness, diffuse uneasiness, generalized irritability, and difficulty in concentrating. There may be mild nausea, loss of weight, heart palpitations for no apparent reason, and cardiovascular changes (Coleman, 1964),

Traditionally, psychology has been concerned with studying phenomena such as anxiety under controlled conditions. Empirical studies of anxiety have used one of two methods. The first method, manipulat1on of subject variables, consists of selecting subjects (Ss) from clinical groups that are characterized by anxiety states. Their 
performance on a wide range of tasks and tests is compared with that of normal non-anxious Ss. However, there are several methodological problems associated with this approach:

The diagnostic label is not a sufficient indication of the momentary state of the patient and does not permit any statement about the relative degree of overt and covert anxiety present. There have been some studies in which tests were given to patients first when they were acutely upset, and then repeated at a later date when the acute state had subsided. . . Such systematic variations, however, have been the exception rather than the rule. More frequently than not, different studies using subjects in the same diagnostic categories lack comparability with regard to the actual state of the subjects when tested (Hanfmann, 1950, p. 58).

The second method of studying anxiety, manipulation of experimental variables, consists of assuming a particular hypothesis regarding the origin of anxiety. The experimenter then attempts to generate anxiety in a normal subject by applying a suitable elicitor, such as physical pain, threat of physical injury, or interference with some physiological need (Maher, 1966).

One of the first experimental investigations of anxiety or fear was undertaken by Watson and Rayner (1920). In this study an 11 month old infant was given a series of fear conditioning trials. These trials consisted of the presentation of a loud noise whenever the infant reached for a white rat. The loud noise resulted in the infant jumping violently, falling forward, whimpering, and generally responding emotionally. Five days later, he was tested for generalization of the emotional response to other objects. The investigators found that the emotional response generalized to a rabbit, a dog, a fur coat, cotton wool, and a Santa Claus mask. Using a different organism, this study was partially replicated by Estes and Skinner (1941) in the conditioned suppression paradigm. 
Conditioned suppression describes the attenuation of an ongoing operant (e.g., lever press or key peck) when a warning stimulus precedes an unavoidable electric shock. Since the temporal relationships between the warning stimulus and shock describe a classical conditioning paradigm, the warning stimulus is referred to as a conditioned stimulus (CS) and the electric shock as an unconditioned stimulus (UCS). In the initial conditioned suppression demonstration, Estes and Skinner (1941) trained rats to lever press on a fixed interval four minute (FI 4) reinforcement schedule. When the FI baseline had stabilized, a $60 \mathrm{~Hz}$ tone was presented for three minutes and terminated with the delivery of shock. At first, neither the tone nor the shock produced any disturbance of the mean rate of responding. However, after several paired presentations the Ss ceased responding during the CS periods. Following the shock presentation, the S's rates recovered to or exceeded the pre-CS levels. The amount of suppression was quantified by forming a ratio of the number of responses made during the CS to the average number of responses made during a pre-CS period of equal duration. They found that the ratio changed from 1.2: 1.00 in the first experimental session to $0.3: 1.00$ in the eighth session. Estes and Skinner concluded that the experimental paradigm conditioned anxiety to the CS. When the CS was later presented, a conditioned emotional response disrupted the ongoing baseline operant behavior. This interpretation has been designated the interference hypothesis. In summary, Estes and Skinner (1941) stated that the procedure "made it possible to follow with ease the development of the 'anticipation' of the shock during subsequent repetitions of the situation" (p. 394). 
Considerable support exists for the interference hypothesis and various indices of the fear state have been suggested. These indices of fear have been classified as either covert respondents or overt behaviors which interfere with ongoing behavior. The covert respondents that have been implicated are heart rate changes (Stebbins and Smith, 1964) and changes in the activity of the endocrine system (Mason, Brady, and Sidman, 1957). However, these studies recorded data only after suppression had been established. Several of the overt responses that have been involved in the development of conditioned suppression are crouching, freezing, urination, and defecation (Brady, and Conrad, 1960; Hunt and Brady, 1955; and Hunt and Otis, 1953).

In addition to an interference hypothesis, conditioned suppression has been explained by a punishment interpretation (Lyon, 1968). This interpretation assumes that in the early stages of acquisition there is a high probability that shock will be delivered to some response in the lever pressing chain during CS presentation. Therefore, the lever pressing chain is punished and the activity is suppressed in the presence of the CS. The unsystematic and post hoc nature of this interpretation has been noted by Church, Wooten, and Mathews (1970):

The punishment theory of CER is untenable, however, for at least three reasons: (1) A signal will produce response suppression when the contingency between signal and aversive event was established in a different apparatus. . . . (2) the critical fact is that the aversive event is not contingent upon a response, i.e., the probability of an aversive event given one or more responses in any interval of time is equal to the probability of an aversive event given no response in that interval of time. . . The principle of adventitious punishment could account for an increase or decrease in response rate with equal plausibility. It has been used post hoc to explain why behavior that emerged must have emerged, but it is a principle seldom invoked in the prediction of behavior. (3) The punishment 
theory of CER implies that differences between punishment and CER are only quantitative, but observers have reported gross differences in the behaviors of subjects under the two procedures. Hunt and Brady (1955) described the CER subject as generally frightened (defecation and immobility) and the discriminative punishment subjects as passive avoiders of a specific instrumental response. . . . (p. 4).

The phenomenon of conditioned suppression has been demonstrated in a wide variety of organisms: goldfish (Geller, 1963, 1964), mice (Sidman, Ray, Sidman, and Klinger, 1966), guinea pigs (Valenstein, 1959), cats (Brady and Conrad, 1960), dogs (Lindsley and Jetter, 1953), albino rats (Estes and Skinner, 1941), white carneaux pigeons (Azrin, 1956), and rhesus monkeys (Brady and Conrad, 1960). In addition, several parameters of the procedure have been investigated: UCS intensity, CS intensity, CS-UCS interval, partial reinforcement effects, stimulus generalization, differential conditioning, higher order conditioning, and reinforcement baseline effects.

\section{UCS Intensity}

One of the first conditioned suppression parameters to be systematically investigated was UCS intensity. In an early review of conditioned suppression 1iterature, Brady and Hunt (1955) state:

In one rather tedious experiment, for example, it has been possible to show that both the rate of acquisition and resistance to extinction of the conditioned emotional response are a function of the intensity of the unconditioned shock stimulus and the number of conditioning trials. Acquisition of the CER was found to be significantly faster and extinction significantly slower as the intensity of the shock and the number of conditioning trials increased ( $p .320$ ).

This UCS relationship in conditioned suppression acquisition has been documented in a series of careful studies by Annau and Kamin (1961), and James and Mostoway (1968). Annau and Kamin (1961) Investigated the UCS intensity relationship using five UCS intensities (0.28-, 0.49-, 
$0.85-, 1.55-$, and $2.91-\mathrm{mA})$. When the rat's response rates stabilized on a VI 2.5 reinforcement schedule, the conditioned suppression procedure was begun. As a pretest, the first experimental session consisted of four three minute periods of a white noise CS with absence of terminating UCS. The Ss were randomly assigned to one of the five groups, each group at a different UCS intensity. During the next 10 days the three minute CS was terminated by the appropriate intensity UCS. Following acquisition of conditioned suppression, extinction was carried out until a predetermined suppression ratio was reached. In this phase the CS was presented for three minutes without any terminating UCS. The results indicated that the degree of suppression and the resistance to extinction were both monotonic functions of UCS intensity. For example, the data from the $0.28-\mathrm{mA}$ group showed no evidence of any suppression effect, however, the Ss flinched and crouched when shocked. The 0.40-mA group showed a U shaped acquisition curve. This would indicate that the Ss showed a moderate degree of suppression early in acquisition, followed by recovery. The three higher intensities $(0.85-, 1.55-$ and $2.91-\mathrm{mA})$ produced rapid acquisition curves that were indistinguishable except in terms of resistance to extinction. In these three groups resistance to extinction was directly related to UCS intensity. In addition, Annau and Kamin reported that high intensity shocks depressed the operant baseline. Similar results were obtained by James and Mostoway (1968) using a consummatory 1ick response as the operant behavior. In this study it was necessary to give the rats several sessions to adapt to the water deprivation schedule. This consisted of a daily 20-minute avallability of water at the $\mathrm{Ss}^{\prime}$ home cages. In the next phase of 
adaption the Ss received their entire daily ration of water in the conditioning chamber. During this time a compound CS was presented in an alternating 30-sec-on, 30-sec-off sequence. Following adaptation to the apparatus, the Ss were randomly assigned to one of four groups of UCS intensity $(0.1-, 0.5-, 1.0-$, and $2.0-\mathrm{mA})$. Al1 acquisition sessions, starting with the S's first lick response, were 10-minutes in duration. Following the S's twentieth lick response CS onset occurred after either 30-, 60-, or 90-seconds. The results indicated that both acquisition and resistance to extinction were increasing monotonic functions of UCS intensity in acquisition. This conclusion is supported by Annau and Kamin (1961), Kamin and Brimer (1963), Hendry and Van-Toller, (1965), Millenson. and Hendry (1967), Notterman and Morton (1958), Singh (1959), and Yashida, Kai, and Imada (1969). James and Mostoway (1968) found that the high UCS intensity groups ( $1.0-$ and $2.0-\mathrm{mA}$ ) showed similar levels of performance in acquisition. However, their performance was differentiated in extinction, where resistance to extinction was directly related to UCS intensity. This increased resistance to extinction was also found by Annau and Kamin (1961) in the high intensity UCS groups (0.85-, 1.55-, and 2.91-mA). A $U$ shaped acquisition curve for all five UCS intensities was found. This recovery from suppression has been found by Annau and Kamin (1961), Hendry and Van-Toller (1965), and Millenson and Hendry (1967).

\section{CS Intensity}

The effects of CS intensity upon conditioned suppression acquisition have been investigated in another series of studies by Kamin and his associates. In the first of these, Kamin and Schaub 
(1963) studied the effect of CS intensity on acquisition in both delayed and trace conditioning procedures. Following rate stabilization on a VI 2.5 reinforcement schedule, rats were randomly assigned to one of three CS intensity groups. The three CS intensities studied were 81 (strong), 62.5 (medium), and $49 \mathrm{db}$ (weak). As a pretest the first experimental session consisted of four three minute periods of appropriate intensity white noise (CS) with the absence of the UCS. During the next five sessions the three minute CS interval was terminated with the UCS in a delayed conditioning procedure. In the next phase the strong CS group and the weak CS group were both subdivided into two groups and extinction was begun. Group one received the strong CS during both acquisition and extinction, group two received the weak CS during both acquisition and extinction, and group three received the strong CS in acquisition and the weak CS in extinction. Group four received the weak CS in acquisition and the strong CS in extinction. The results indicated that the strong CS group ( $81 \mathrm{db}$ ) acquired conditioned suppression most rapidly. The three CS intensity groups converged at an asymptote of complete suppression within five sessions. In terms of resistance to extinction, once the $\mathrm{S}$ had been conditioned to a specific CS intensity any change in intensity accelerated extinction. The effects of CS intensity using a trace conditioning procedure were investigated in the second part of the Kamin-Schaub study. The training and shock values duplicated the first part of the study except that the CS was two minutes in duration. The UCS followed CS offset by one minute. After 10 sessions of acquisition, the strong CS group had acquired conditioned suppression. However, the weak CS group exhibited no signs of conditioned suppression. 
A study by Kamin and Brimer (1963) supports the Kamin and Schaub (1963) findings. Kamin and Brimer (1963) used a 3 X 3 analysis of variance design to evaluate the effects of three CS and UCS intensities upon acquisition. The CS values were 47,60 , or $81 \mathrm{db}$, while the UCS values were 0.28-, 0.49-, or $0.85-\mathrm{mA}$. Following response stabilization on a VI 2.5 schedule, the rats were randomly assigned to one of the nine groups. After one session of pretesting, acquisition was begun with the appropriate CS and UCS intensities. The results indicated a significant tendency for the high intensity UCS to produce a greater suppression than the moderate intensity UCS. There was no evidence for suppression at the low intensity UCS. A significant interaction between CS and UCS intensity was also reported. "The interaction is obviously attributable to the failure of the low CS to be very effective with the medium US; the low CS is very effective with the high US" (Kamin and Brimer, 1963, p. 199).

According to Beecroft (1967), these two studies (Kamin and Schaub, 1963 and Kamin and Brimer, 1963) and data from Kamin (1965) allow one to draw several conclusions about CS intensity. First, high intensity CSs produce conditioned suppression acquisition more quickly than low intensity CSs. Second, conditioned suppression will not develop when a weak CS is paired with a weak ICS. Third, intensity decreases can function as CSs (Kamin, 1965).

\section{CS-UCS Interva1}

The conditioned suppression literature contains few studies investigating CS-UCS intervals. The first investigation of interstimulus intervals was undertaken by Libby (1951). Using a delayed 
conditioning procedure, Libby (1951) studied seven CS-UCS intervals: 1-, 4-, 7-, 10-, 20-, and 30-seconds. Rats were randomly assigned to one of the seven groups and then placed on a 22 hour feeding rhythm for several days. During the first three sessions each $S$ received 10 pairings of a light CS and a shock UCS in a Mowrer "grill box" at the appropriate CS-UCS interval. Following the shock conditioning sessions, Ss were trained to lever press on continuous reinforcement for three sessions. The fourth session was the first test day consisting of the following sequence of trials: (1) 10-minutes of continuous reinforcement in the absence of light; (2) 10-minutes of continuous reinforcement in the presence of continuous 1ight; (3) 25-minutes of continuous reinforcement in the absence of 1ight. During the test sessions all lever presses were reinforced. The measure of response suppression was the difference between response rates in the initial 10-minute dark period and the 10-minute light period. The results tended to indicate that the amount of suppression increased as the CS-UCS interval increased from 0 to 10 seconds. The light did not acquire any greater suppressive properties beyond 10-seconds, and seemed to fall off beyond 20seconds.

Dyal and Goodman (1966) attempted to replicate Libby's findings. They employed a procedure in which the CS was a response contingent secondary punisher. During the first half of each session rats were given continuous reinforcement training (CRF). In the second half of the session the Ss were placed in a fear conditioning chamber. Following 5minutes in the apparatus, the CS was presented and terminated by the UCS after an appropriate interval. The CS-UCS intervals used were 0.5-, 5-, 15-, 30-, and 60-seconds. During the sixth session, the Ss were 
placed in the operant chamber and given five minutes of CRF. Following this period, each lever press produced a food pellet and CS. Dyal and Goodman found substantial suppression in all groups. The total number of responses during the suppression period were analyzed with an analysis of variance. No differential effects of the CS-UCS interval during either acquisition or extinction were indicated. Although the results are contrary to Libby (1951), Dyal and Goodman (1966) state:

It is our feeling that the lack of differential effects of CS duration in the present experiment may have been due to the fact that the . . . procedure did not require the operant to be trained to a sufficiently stable level. As a result, variability during the suppression test is quite high and thus masked whatever CS duration effect may have been present (p. 250).

Several studies by Kamin $(1961,1965)$ deal with the temporal parameters within which conditioned suppression can be acquired. In the first study, Kamin (1965) used a trace conditioning procedure. Three groups of rats were trained with a 1.5-second CS, where CS onset preceded UCS onset by either 61.5-, 75-, or 180-seconds. The fourth group was trained with a 15-second CS, CS onset preceding UCS onset by 75-seconds. The fifth group was trained with a 120-second CS, CS onset preceding UCS onset by 180 seconds. Kamin (1965) found that the 61.5-second group showed a typical abrupt acquisition curve. The 180-second groups showed no acquisition, while the 75-second groups showed a slow acquisition curve. These results indicate that in trace conditioning suppression falls off rapidly beyond a 61.5second CS onset. This conclusion was supported in a second trace paradigm study by Kamin (1965).

In the second study, two CS durations were examined in confunction with four CS-UCS intervals. The CS durations were either 1.5- or 
15-seconds, while CS onset occurred either 75-, 105-, 135-, or 180-seconds before the UCS onset. As in the first study the greatest suppression was found at the shorter CS-UCS intervals. As the intervals from CS onset increased, less suppression was noted.

In the third study the intervals between CS onset and UCS onset were held constant at 180-seconds for all groups. The CS durations were 1.5-, 15-, 120-, 175-, 179.5-, 180-, and 185-seconds. In terms of intervals between CS termination and UCS onset, it equals 178.5-, 165-, 60-, 5-, .5-, 0-, and -5-seconds. The first five intervals represent a trace conditioning procedure while the last two are delayed conditioning. Kamin found that in trace conditioning no suppression uccred during the long intervals. However, at the shorter intervals where CS persisted to within 5- or .5-seconds of the UCS onset, slow acquisition was noted. The delayed conditioning groups showed good suppression up to a maximum delay of 180-seconds.

Kamin (1961) employed four CS durations with a 180-second interval between CS onset and UCS onset. The CS durations were 0.5-, 1-, 2-, or 3-minutes. Thus, in the 0.5-minute group, CS offset was 150-seconds before UCS onset; in the 1-minute group, CS onset was 120-seconds before UCS onset; in the 2-minute group, CS offset was 60-seconds before UCS onset; and in the 3-minute group, CS offset was 0-seconds before UCS onset. The procedure used with the first three groups was trace conditioning, while the procedure used with the fourth group was delayed conditioning. The 150-second group showed complete suppression. The $120-$ and 60-second groups acquired suppression gradually.

Kamin's studies $(1961,1965)$ indicate that in trace conditioning suppression is acquired at interstimulus intervals from 0.5 to 120 seconds. 
However, conditioning falls off rapidly after 60-seconds. Conversely, suppression is acquired in a delayed conditioning paradigm at interstimulus intervals greater than 180-seconds.

\section{Partial Reinforcement}

The partial reinforcement effect (PRE) has been observed in several conditioned suppression studies. The PRE refers to greater resistance to extinction for partial than for $100 \%$ reinforcement. Brimer and Dockrill (1966) trained rats to lever press on a VI 2.5 schedule. Following response stabilization, the Ss were randomly assigned to one of three groups. In the E-50\% group, the Ss recelved four CS presentations, two of which were terminated with the UCS. The E-100\% groups were trained under 100\% UCS termination, receiving either two or four CS-UCS presentations per sessions. The Ss were run until a specified suppression criterion was reached and then the UCS was discontinued and extinction data collected. The results indicated that the $100 \%$ group that received two CS-UCS presentations per session, required fewer trials to reach criterion than either of the other groups. However, the E-50\% group displayed more resistance to extinction than the other groups. In the second part of the experiment the procedure was duplicated except that an E-25\% group was substituted for the E-50\% group. As in the first part of the study, the E-25\% group required more trials to reach criterion, but were more resistant to extinction.

The PRE effect has also been found by Wagner, Siegel, and Fern (1967) and Willis and Lundin (1966). Wagner, Siegel, and Fern (1967) found that the E-50\% group was more resistant to extinction than the 
E-100\% group. However, there was no significant difference between the experimental groups on the last session of acquisition.

Using a within subjects design, Willis and Lundin (1966) found that suppression was greatest in the E-90\% group than in the E-50\% group. There was almost no suppression in the $\mathrm{E}-10 \%$ group. This supports the findings that the lower the percentage of CS presentations terminated with UCS, the lower the acquisition function.

In the only study that does not confirm PRE, Geller (1964) found slower acquisition in the E-50\% group than in the E-100\% group. However, the E-50\% group extinguished more rapid1y than the E-100\% group. Since Geller (1964) used goldfish as Ss, he postulated that the fallure to replicate $\mathrm{PRE}$ could have been because of organismic differences between goldfish and rats. In a footnote Geller reports the PRE using the above procedure with rats as Ss.

\section{Stimulus Generalization}

Ray and Stein (1959) used rats in documenting the generalization of conditioned suppression. The Ss were trained to lever press on a VI 2 schedule. When responding had stabilized, differential conditioned suppression acquisition was begun. In the acquisition procedure an $1800 \mathrm{~Hz}$ tone was always terminated with the UCS, while a $200 \mathrm{~Hz}$ tone was never terminated with the UCS. After several sessions a stable discrimination was established. Responding was completely suppressed in the $1800 \mathrm{~Hz}$ periods, while the response rates were normal during the $200 \mathrm{~Hz}$ periods. In the following phase, only two of the four CSs were terminated by UCSs in order to minimize extinction effects during generalization testing. The generalization test tones were 560, 980, 
1120 , and $1500 \mathrm{~Hz}$. Generalization testing consisted of substituting two presentations of one of the test tones in place of the non-shocked tones. The results indicated that the strength of suppression for the test stimuli was directly related to its similarity to the $1800 \mathrm{~Hz}$ reinforced CS.

Using a more conventional procedure, Desiderato (1964) obtained generalization gradients. The rats were randomly assigned to one of five groups which differed only in CS frequency used during acquisition. The CS frequencies used were $3500,2280,1500,1000$, and $670 \mathrm{~Hz}$. Following attainment of the suppression criterion, only two of the five CS presentations were terminated with UCS. Again, when the suppression criterion was met the generalization testing was begun. In generalization testing one of the five tones was the original CS, while the other four were generalization test stimuli. The UCS was never presented during generalization testing. The results suggested that the amount of responding in the presence of the generalization test stimuli was directly related to it similarity to the original training CS. Similar results have also been described by Winograd (1965) with rats and by Hoffman and Fleshler (1961) with pigeons.

\section{Differential and Higher-Order Conditioning}

In a previously cited study (Ray and Stein, 1959) a differential conditioning procedure was used to obtain generalization gradients. Ayres (1966) established a differential conditioning procedure in order to evaluate the Eggar-Miller (1962) information hypotheses. The rats were trained to lever press on a VI 60 second schedule. Following response stabilization, the CS was presented to establish a baseline. 
One-half of the Ss received tone-light-light-tone presentations for the four CS presentations, while the other half of the Ss received lighttone-tone-light presentations. In acquisition training the Ss were assigned to one of five groups matched for response rate. In evaluating differential conditioning there are only two groups that are important, group D and E. Group D received 10 pairings of stimulus one $\left(\mathrm{CS}_{1}\right)$ with the UCS and 10 occurrences of stimulus $2\left(\mathrm{CS}_{2}\right)$. Group E received 10 pairings of $\mathrm{CS}_{2}$ with the UCS and 10 occurrences of $\mathrm{CS}_{1}$. For one-half of the Ss in each group, CS was light and $\mathrm{CS}_{2}$ was tone and vice versa for the other Ss. In order to allow rats to recover after the training phase, Ss were given one additional, session of VI 60 seconds with no shock, light, or tone. The Ss were then given four sessions identical to the original baseline session and the suppression ratios were calculated. The results indicated that $\mathrm{CS}_{1}$ shock group suppressed to $\mathrm{CS}_{1}$ and not $\mathrm{CS}_{2}$. The $\mathrm{CS}_{2}$ shock group suppressed to $\mathrm{CS}_{2}$ and not $\mathrm{CS}_{1}$. In a similar study Hammond (1966) demonstrated differential conditioning using different modality CSs. When the VI 60 second baseline had stabilized, a $3000 \mathrm{~Hz}$ tone was terminated by the UCS, while a flashing light was presented without UCS termination. Hammond found significant suppression to the $3000 \mathrm{~Hz}$ tone. However, no suppression was noted to the flashing light.

Although there are several studies documenting differential conditioning in conditioned suppression, there is only one study that offers evidence of higher order conditioning. Davenport (1966) trained rats to lever press on a VI schedule. When the rates had stabilized each of the different CSs (pilot light, pulsating buzzer, 6.8 clicks- 
per-second, and $800 \mathrm{~Hz}$ tone) were presented several times to habituate novelty effects. The first order conditioning phase consisted of pairing one of the CSs $\left(\mathrm{CS}_{1}\right)$ with UCS in a delayed conditioning procedure. After several sessions, the Ss were tested for generalization of suppression to the other CSs. In contrast to previous research Ray and Stein (1959); Hoffman and Fleshler (1961); Desiderato (1964); and Winograd (1965) little generalization of suppression was found. During the next phase, the UCS was omitted and the onset of second order CS $\left(\mathrm{CS}_{2}\right)$ preceded the onset of the original $\mathrm{CS}\left(\mathrm{CS}_{1}\right)$. Control Ss received the same durations of $\mathrm{CS}_{1}$ and $\mathrm{CS}_{2}$ but in a backward order. The results suggested that second order conditioning was readily obtained in the experimental Ss. The investigators reported that 32 of the 36 experimental Ss displayed second order conditioning in the form of at least partial and constant suppression in the presence of $\mathrm{CS}_{2}$ alone. In contrast, none of the 16 control Ss exhibited even partial suppression.

\section{Reinforcement Baseline}

The effect of reinforcement schedules upon baseline maintenance has been the subject of several investigations. Brady (1955) trained rats to lever press on $\mathrm{CRF}$. When response rates had stabilized, conditioned suppression acquisition was introduced. The CS was a click presented for three minutes, beginning at the fourth minute and terminating at the sixth minute with UCS. After extensive training the Ss were assigned to one of six groups, matched for both response rate and suppression. Each group received additional dally runs without CS or UCS. Group one recelved CRF; group two recelved FR 6; group three 
rec fved FR 12; group four received VR 12; group five received VI 1 minute; group six received VI $30 \mathrm{sec}$. When lever pressing had stabilized for all groups, the Ss were tested for retention of suppression. The test sessions consisted of three minute presentations of CS without UCS on the respective reinforcement schedule. During the 10 extinction test sessions there were clear differences between the various groups. The Ss trained on ratio schedules extinguished most quickly, while Ss on interval schedules extinguished most slowly. The Ss trained on the CRF schedule maintained an intermediate rate of responding in extinction. Recovery of the lever press rate following the first response in the presence of the click was abrupt for the ratio schedules and more gradual for the interval schedules. Stein, Sidman, and Brady (1958) studied CS duration and found that the number of reinforcements obtained under the various conditions was fairly constant. Sufficient training resulted in animals suppressing in the CS period only to the extent that they did not markedly reduce opportunities for positive reinforcement. In this study the Ss lever pressing was allowed to stabilize on VI schedules. Following stabilization, the acquisition procedure was introduced. The sessions consisted of VI reinforcement with different CS and intertrial interval durations.

The Stein, Sidman, and Brady (1958) study suggests that the magnitude of suppression is reduced only to the extent that it resulted in missed reinforcements. Whether this was due to the total number of reinforcements missed per session or the average reinforcement density of the schedule was not stated. Carlton and Didamo (1960) held the number of reinforcements constant for the experimental sessions. The 
rats were trained to lever press for VI 2 reinforcements. When the rates stabilized, acquisition training was introduced. In a procedure similar to that of Stein, Sidman, and Brady (1958) the interval between tone presentations was decreased, while the duration of the tone was held constant at three minutes. During this phase the number of reinforcements each $S$ received was equal to the mean number received in the last session of acquisition training. Therefore, the Ss could not lose reinforcements, regardless of the amount of suppression. As the relative amount of time of CS presentation increased, suppression decreased. Carlton and Didamo (1960) state that:

Since the total number of reinforcements delivered was constant throughout the experiment, the hypothesis that the total number of reinforcements missed attenuates suppression probably can not account for these data (p. 257).

They concluded that it was the density of reinforcement and not the total number of reinforcements lost that was the important variable. The finding that reinforcement density or local reinforcement rate was an important variable was investigated by Lyon (1963) using a multiple schedule. Two pigeons were trained on CRF and then VI 1 before being transferred to a multiple VI 1 VI 4 reinforcement schedule. When the rates had stabilized and a discrimination had emerged, acquisition was begun. The CS consisted of interruption of houselights and was followed by the UCS. The cumulative record showed gradual suppression during the CS interval in the VI 1 component, while the rate immediately decreased to zero in the VI 4 component. Recovery was faster for the VI 1 component than for the VI 4 component. It would appear from this study that suppression is less 
severe when the baseline is maintained by high density reinforcement than when maintained by low density reinforcement. The study failed, however, to control for changes in response rate produced by variation in reinforcement frequency. Therefore, it is possible that response rate per se might be a determinant of the degree of suppression.

Lyon (1965) investigated the effect of changes in response rate holding the frequency of reinforcement constant. When the pigeons' rates had stabilized on a VI 1 schedule, a multiple VI 3 FR 50 schedule was introduced. Following response stabilization the conditioned suppression procedure was introduced in the VI 1 component of the multiple schedule. Complete suppression resulted during this component. After suppression was stable, the ratio requirement for the FR component was increased to 75 and later 100. An increase in the response rate resulted during the VI 3 component, while, no change in the degree of suppression was evident. "Thus, neither an increase in the baseline response rate or an increase in the relative reinforcement frequency affect conditioned suppression on a variable interval schedule of reinforcement" (Lyon, 1965, p. 444).

Blackman (1966) presents two studies which do not support the Lyon (1965) results. Blackman (1966) exposed one group of rats to a variable ratio schedule that was increased from VR 2 to VR 100 over a period of 60 sessions. The other group was exposed to CRF for 60 sessions. In the VR group, sessions 61 to 107 consisted of reinforcement on a VR 100 schedule. The CRF group, however, was placed on a variable interval schedule in which reinforcement was available only when one was obtained by the matched animal in the VR group. During sessions 103 to 107, the conditioned suppression procedure was superimposed on 
baselines in which reinforcement frequency was identical and response rates varied. In all cases there was more suppression in the VR schedule than in the VI schedule. The second study confirmed that conditioned suppression was more severe with low response rates than with higher response rates. Blackman (1966) states:

The results of the two experiments presented provide evidence that, when reinforcement frequency is controlled, response rate is a determinant of conditioned suppression, high response rates producing more disruption. This conclusion is not in agreement with that proposed by Lyon (1965). However, it is thought that there is no contradiction between the present results and results obtained by Lyon. It will be recalled that, after establishing complete suppression against a VI 3 baseline, Lyon induced an increase in response rate on that schedule. The present results suggest that this should produce more disruption by conditioned suppression training, but such an increase cannot be exhibited by Lyon's subjects. It appears therefore that the behavioral measure used is insensitive to the effects of the experimental manipulations. It might also be mentioned that Lyon did not control for possible sequence effects an objection that does not apply to the present work (p. 693).

Although this conclusion may hold for VI or VR reinforced behavior, suppression on FI or FR reinforced behavior seems to be determined by the temporal proximity of the CS onset to the scheduled reinforcement (Lyon, 1964; Lyon and Felton, 1966).

\section{Statement of the Problem}

Several investigators have suggested that conditioned suppression is a by-product of classically conditioned fear. In general, this assertion is based upon the operational and parametric similarities of the conditioned suppression and classical conditioning paradigms. Such parametric similarities have been shown in acquisition, extinction, differential conditioning, higher order conditioning, stimulus generalization, partial reinforcement effect, and CS and UCS intensity effects. 
However, conditioned suppression is acquired at longer interstimulus intervals than those ordinarily employed in investigating classically conditioned CRs such as eye blink, GSR, and finger withdrawal. For example, three to five minute CS-UCS intervals have been commonly employed in the conditioned suppression paradigm (Kamin, 1961, 1965; Estes and Skinner, 1941). Data from Kamin (1961, 1965) suggests that conditioning occurs using a trace paradigm at interstimulus intervals ranging from one-half to 120 seconds, while delayed conditioning is acquired at intervals exceeding 180 seconds. With a delayed paradigm, Libby (1951) investigated seven interstimulus intervals ranging from 1 to 30 seconds. However, there are several methodological problems associated with this study. Libby (1951) used a Mowrer "grill box" to condition "fear" to the light instead of the procedure of Estes and Skinner (1941). In addition, the test procedure for degree of suppression acquisition consisted of a series of UCS extinction trials instead of the procedure of Estes and Skinner (1941) which was standardized in a series of studies by Kamin $(1961,1965)$.

With a number of modifications, the proposed study will replicate that of Libby (1951). The study will employ a consummatory lick response as an operant. Since the lick response is emitted at a higher rate than the bar press response, the procedure allows the investigation of short CS-UCS intervals. In a training procedure similar to Estes and Skinner (1941), a tone CS terminating with shock will be superimposed on the ongoing operant behavior and the effect on the rate of responding will be recorded. 
CHAPTER II

METHOD

\section{Subjects}

The Ss were 32 male rats of the Sprague-Dawley strain. They were 45 days old at the beginning of adaptation to the water deprivation schedule. The Ss were maintained under 24 hour water deprivation, and received 5-minutes access to water following the test trials.

\section{Apparatus}

A Scientific Prototype rat chamber (with the manipulandum and food cup removed) was located inside a sound-attentuating chamber. A white 5-w houselight was continuously illuminated and located in the right corner of the chamber. The Ss were observed through a two way mirror located on top of the chamber. A water bottle tube was located one inch above the floor and two inches from the left wall. The CS was a $1000 \mathrm{~Hz}$ tone of moderate intensity (approximately $45 \mathrm{db}$, re: $.0002 \mathrm{~d} / \mathrm{cm}^{2}$ ) produced by a Hewlett-Packard audio generator. The UCS was a 1.00 mA shock supplied by a Grason Stadler shock generator and delivered through the grid floor for one-half second.

\section{$\underline{\text { Procedure }}$}

Initially, Ss were randomly assigned. to one of eight experimental groups which differed only in the CS-UCS interval at which they were 
trained and tested. The CS-UCS intervals at which the Ss were trained were $1,3,-7$, and 30 -seconds. The testing intervals were $3-$ and $30-$ seconds. Using a procedure similar to James and Mostoway (1968) and Burdick and James (1970), pretraining consisted of six days adaptation to the water deprivation schedule. During adaptation, the water bottle was available at the home cage for 20-minutes each day. Two days followed in which the Ss were adapted to the apparatus. During these two days the Ss received their entire daily 10-minute water ration in the chamber, and the Cs was presented 10 times in a 30-second-on, 30-secondoff alternating sequence. The number of lick responses were recorded for all Ss in both periods and suppression ratios were, calculated. The suppression ratios were analyzed by a 1 x 8 analysis of variance.

For 16 trials the Ss received one training trial with UCS and one test trial with UCS omitted. During extinction they received two 30-second test trials with UCS omitted. In both acquisition and extinction CS onset was programed to occur randomly either 30-, 60-, or 90-seconds after the $\mathrm{S}^{\prime}$ 's twentieth lick response. Test trials in acquisition (or the second trial in extinction) followed the twentieth lick response by one minute. Two minutes after the completion of the last test trial, the Ss were removed from the apparatus. Suppression ratios were calculated daily by the following formula: $S R=B /(A+B)$, where A equals the number of responses during a 6-second interval of time immediately preceding the CS, and B equals the number of responses during the CS. The dependent variables were the daily suppression ratios and the number of trials to extinction following acquisition (suppression ratio of above 0.450 for at least 3 out of 4 days). The 
suppression ratio data were analyzed by a $2 \times 4 \times 16$ analysis of variance, with repeated measures on the third variable (trials). Extinction data were analyzed by a $2 \times 4$ analysis of variance. 
CHAPTER III

RESULTS

Habituation training was instituted prior to acquisition training. During two sessions, the tone CS was presented in a 30-second-on, 30-second-off sequence, and suppression ratios were calculated for each group of Ss. The suppression ratios for habituation are presented in Appendix A. A one way analysis of variance was calculated on the habituation data. No significant differences were found to exist between the groups prior to acquisition training. The group means and standard deviations are presented in Table 1 . The results of the analysis are represented in Table 2 .

\section{TABLE 1}

MEANS AND STANDARD DEVIATIONS: HABITUATION SUPPRESSION RATIOS

\begin{tabular}{ccc|c}
\hline \hline Group & (Training-Test) & Mean & Standard Deviation \\
\hline 1 & $(1-3)$ & .5625 & .0282 \\
2 & $(3-3)$ & .5438 & .0583 \\
3 & $(7-3)$ & .5302 & .0282 \\
4 & $(30-3)$ & .5200 & .0200 \\
5 & $(1-30)$ & .5450 & .0331 \\
6 & $(3-30)$ & .4962 & .0362 \\
7 & $(7-30)$ & .5372 & .0282 \\
8 & $(30-30)$ & .5080 & .0282 \\
\hline
\end{tabular}


TABLE 2

ANALYSIS OF VARIANCE: HABITUATION SUPPRESSION RATIOS

\begin{tabular}{|c|c|c|c|c|c|}
\hline Source & ss & $\mathrm{df}$ & & $\mathrm{ms}$ & F \\
\hline Between & .010 & 7 & & .0014 & 0.933 \\
\hline Within & .037 & 24 & $\cdot$ & .0015 & \\
\hline Total & .047 & 31 & & & \\
\hline
\end{tabular}

Following habituation, acquisition training was introduced for all Ss and continued for sixteen trials, each containing two trials per day. The first trial (training) consisted of a CS-UCS pairing at the appropriate interstimulus interval. The second trial (test) was a single presentation of the CS. Suppression ratios were calculated from daily test trial data only. The suppression ratios for acquisition and extinction are presented in Figures 1-8. The raw data are contained in Appendix B. Figures 1-8 indicate that after one training trial the suppression ratios for all groups, except the three second training-three second test (3-3), remained at a suppression ratio of approximately 0.50 . However, following the second CS-UCS pairing the suppression ratios decreased rapidly. For example, following the second pairing the suppression ratios ranged from 0.004 $(3-30)$ to $0.2495(7-30)$. During the last two to six sessions, the suppression ratios increased for all groups.

Table 3 presents the means and standard deviations for the acquisition data, which were subsequently analyzed by a three way analysis of variance with two levels of test, four levels of training, 



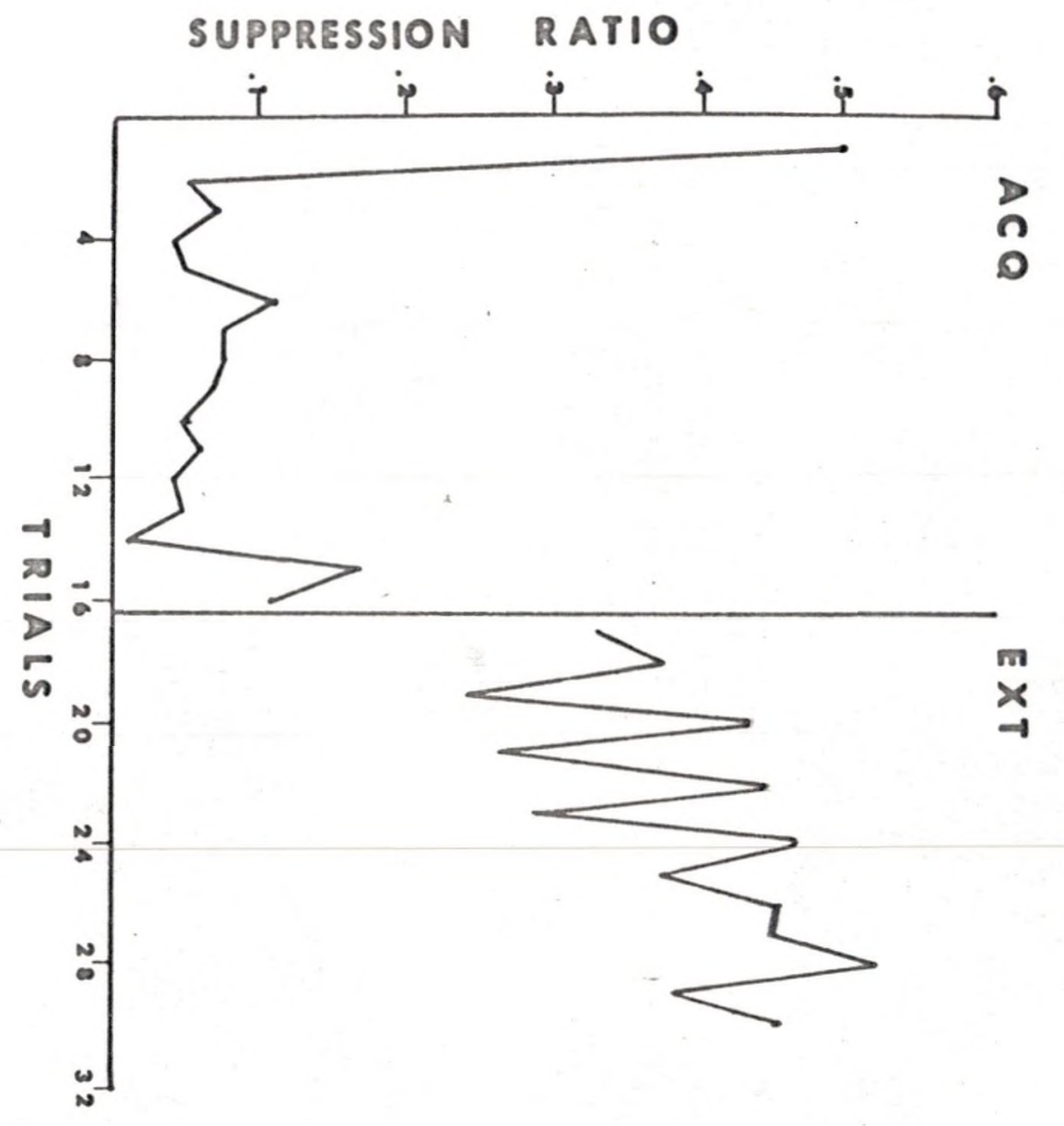





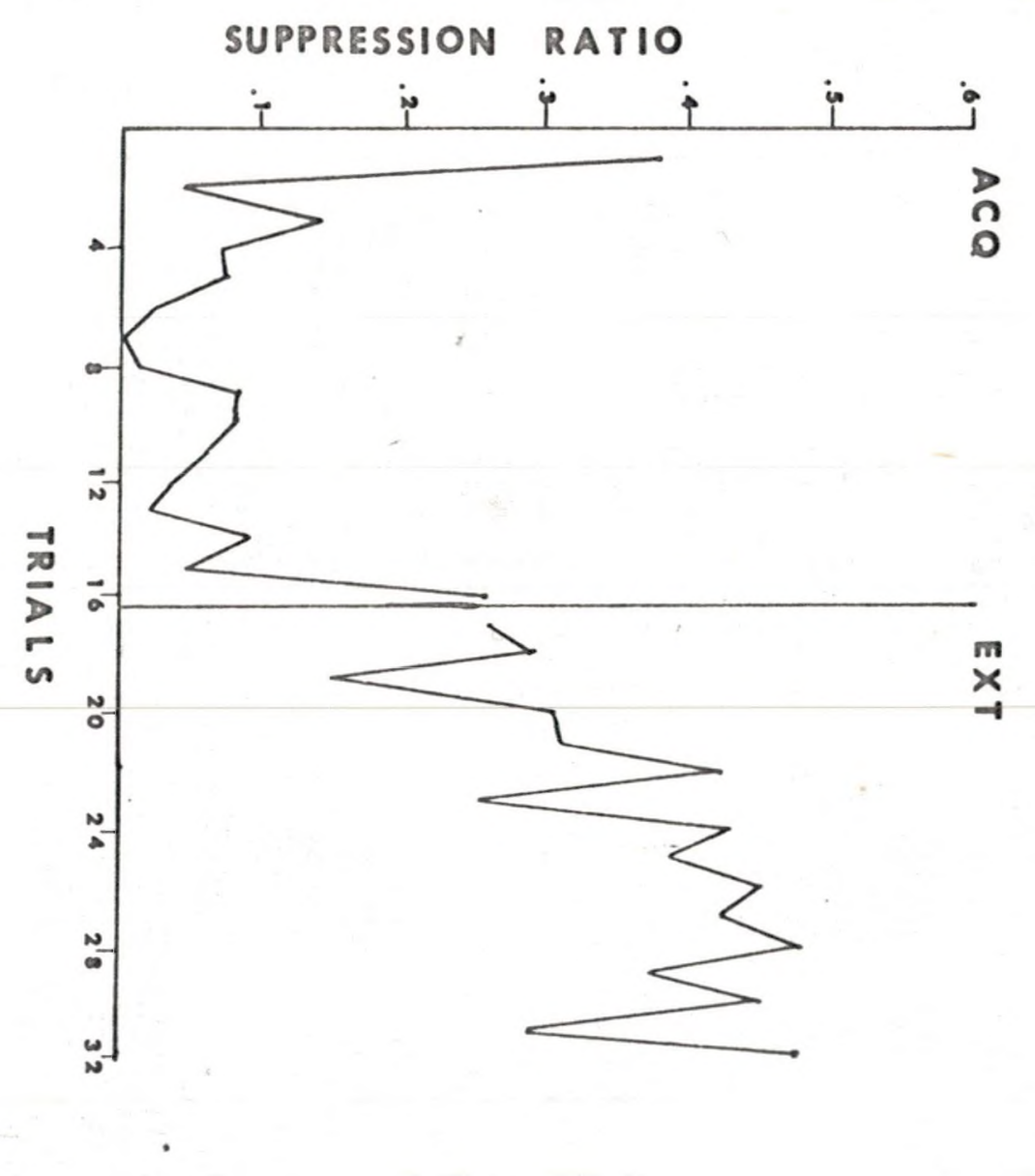





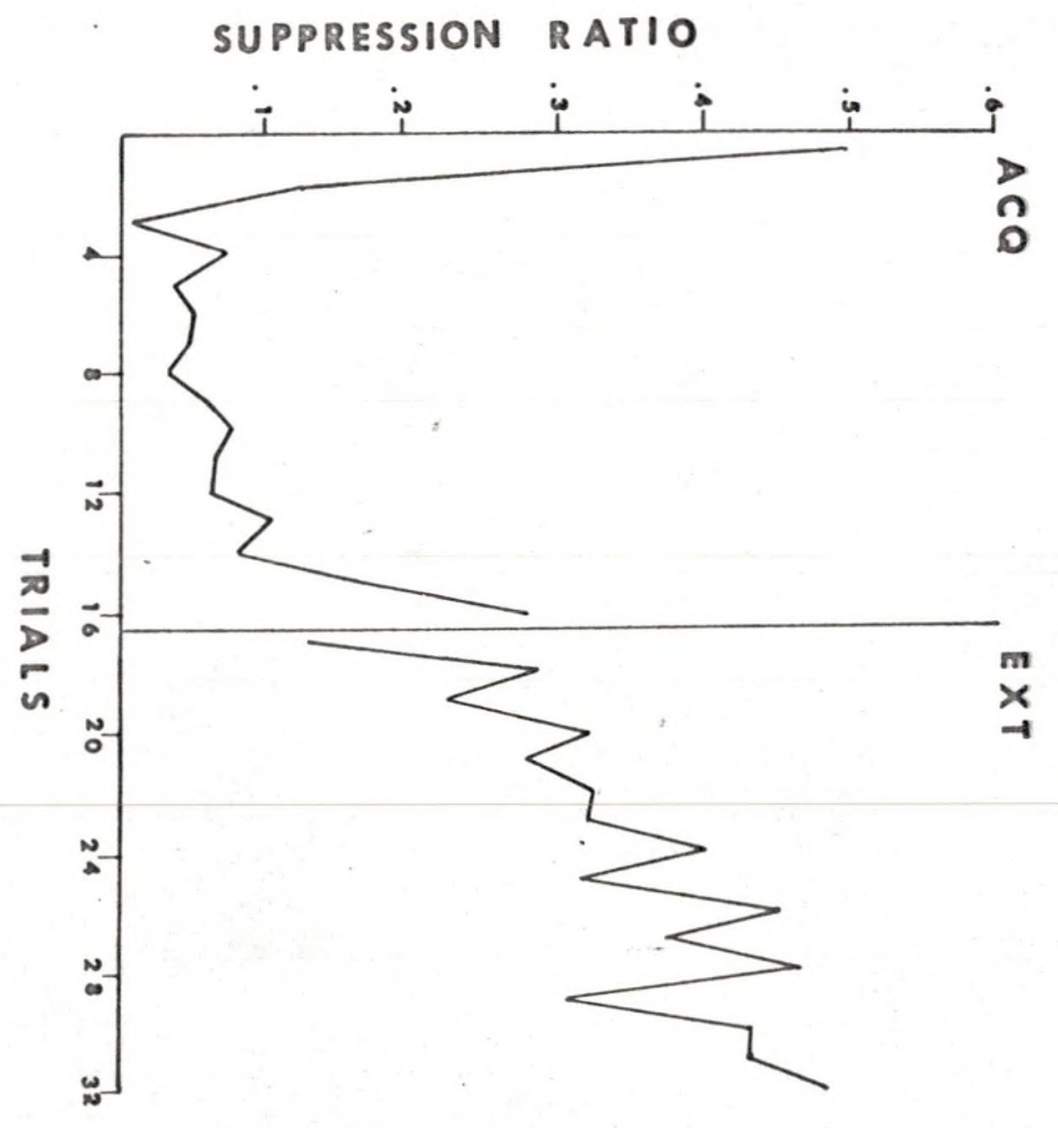





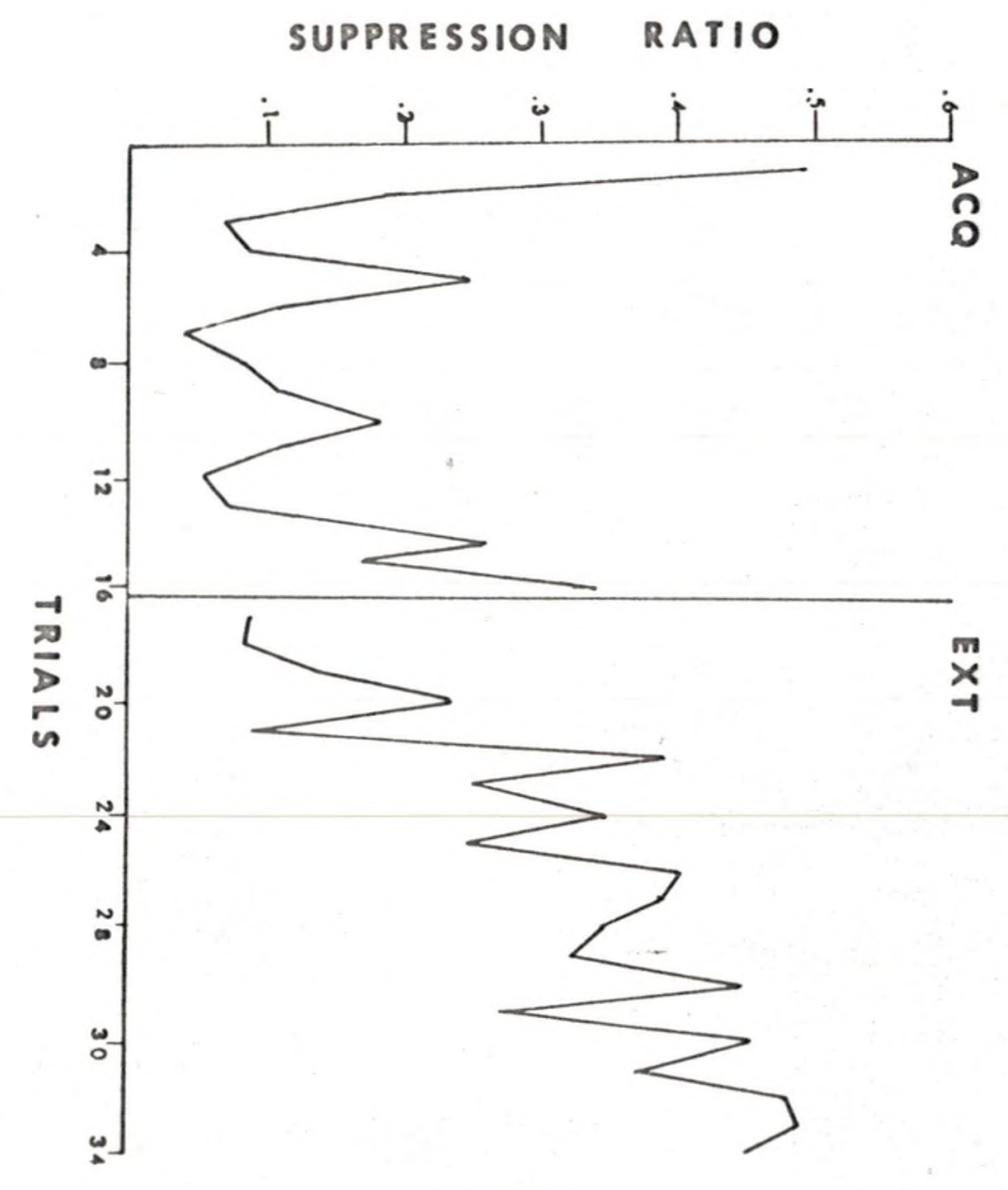





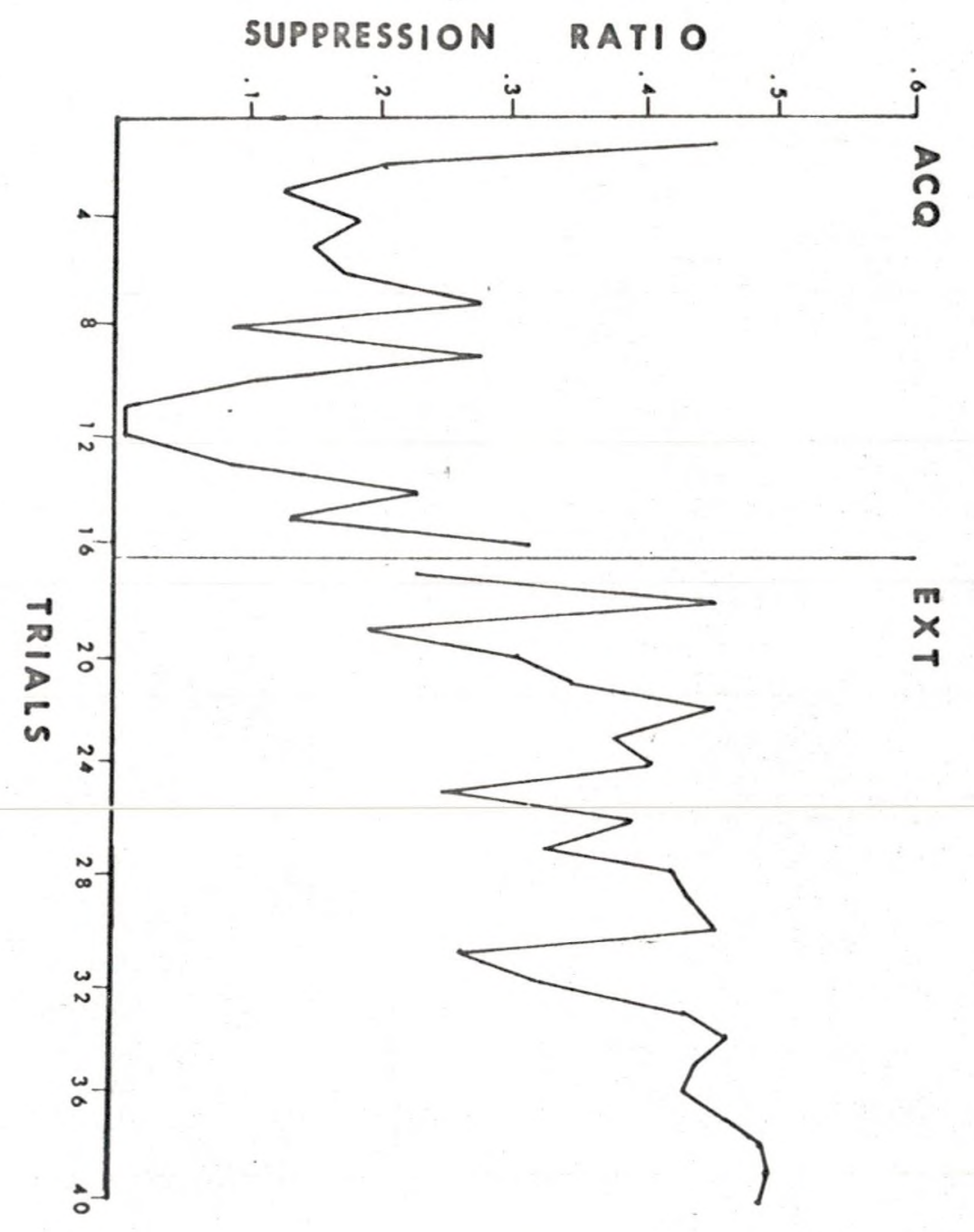


Fig. 6.--Suppression Ratios for Group 6, 3-Second Training 30-Second Test. 


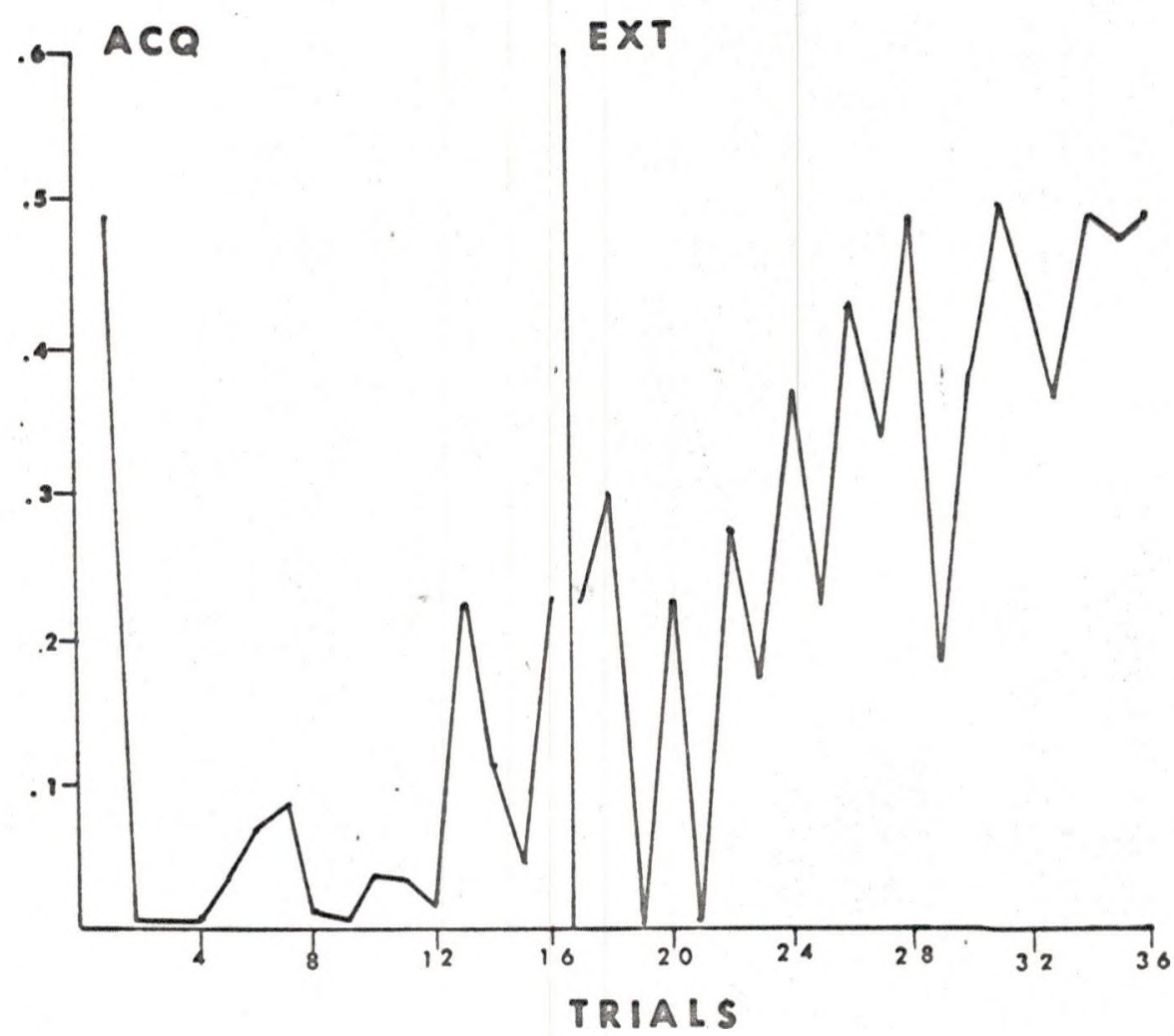





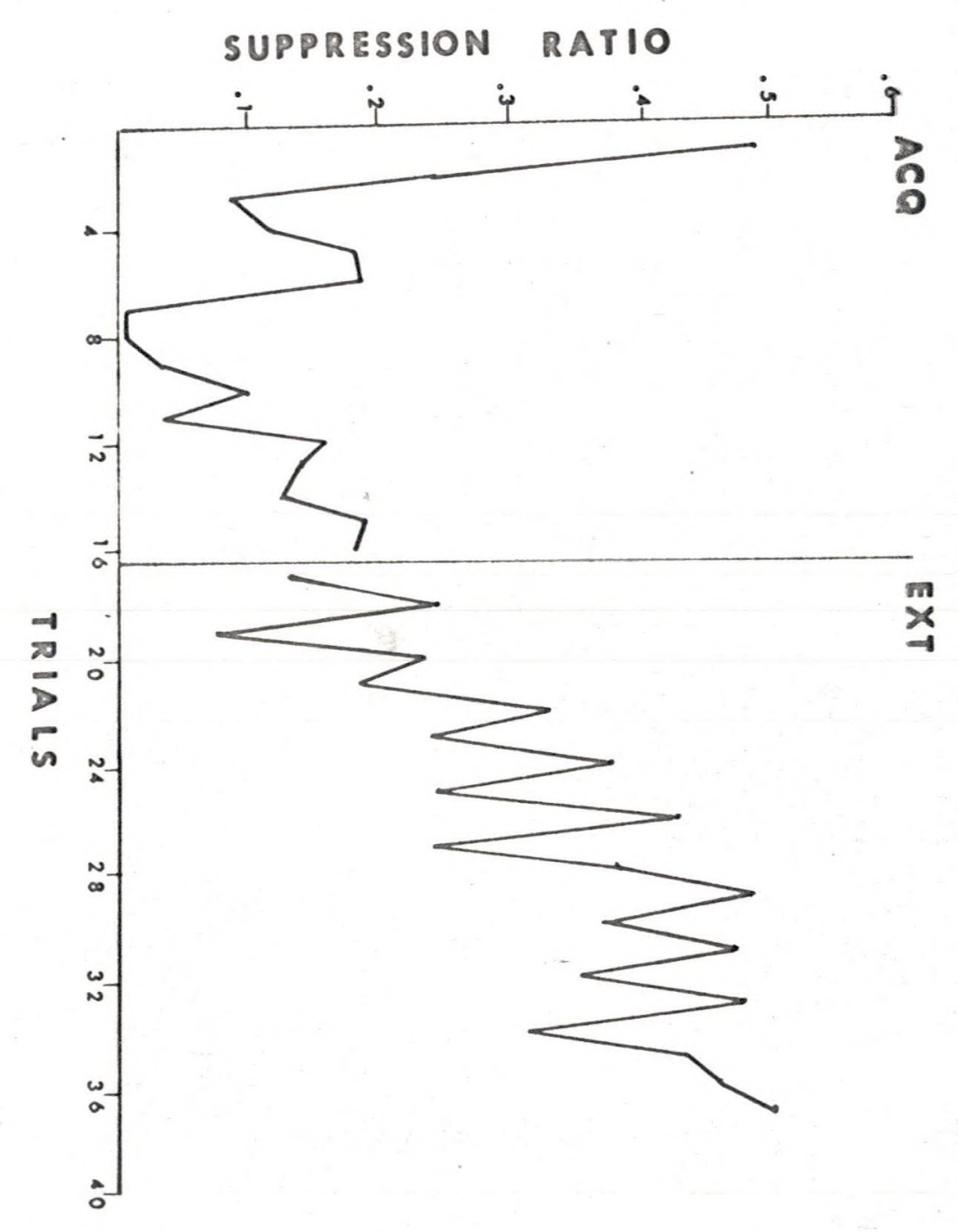





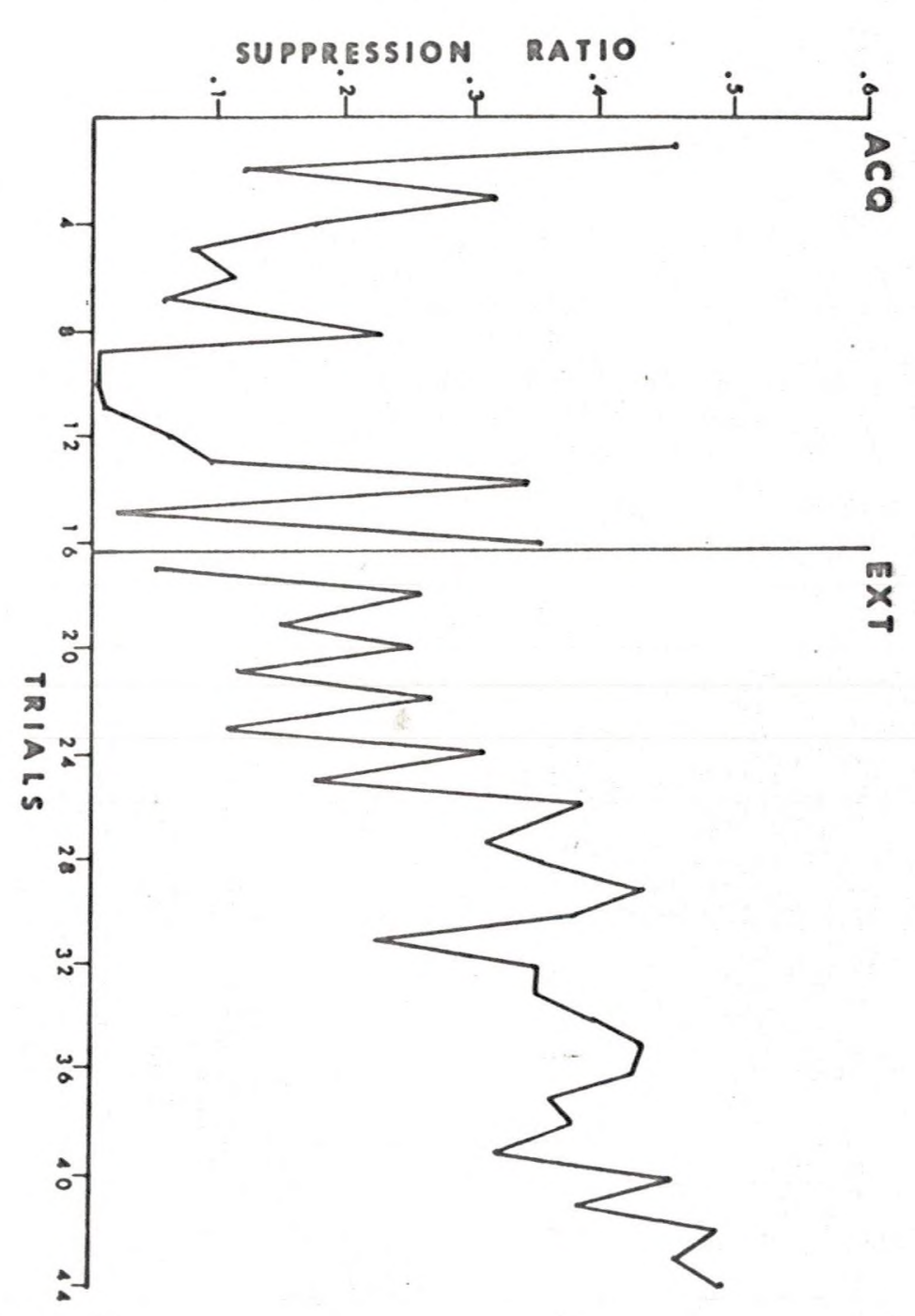


and 16 levels of trials. Repeated measures were made on the sessions variable. The assumption of homogeneity of variance was valid, as indicated by the Hartley $F-\max$ test $(F-\max =2.7907, \mathrm{df}=3, \mathrm{k}=8$ ). The results of the three way analysis are summarized in Table 4.

TABLE 3

MEANS AND STANDARD DEVIATIONS: ACQUISITION OF SUPPRESSION RATIOS

\begin{tabular}{cccc}
\hline Group & (Training-Test) & Mean & Standard Deviation \\
\hline 1 & $(1-3)$ & .0888 & .1287 \\
2 & $(3-3)$ & .0897 & .1126 \\
3 & $(7-3)$ & .1100 & .1383 \\
4 & $(30-3)$ & .1627 & .1681 \\
5 & $(1-30)$ & .1749 & .1881 \\
6 & $(3-30)$ & .0881 & .1577 \\
7 & $(7-30)$ & .1385 & .1694 \\
8 & $(30-30)$ & .1509 & .1813 \\
\hline
\end{tabular}

TABLE 4

ANALYSIS OF VARIANCE: ACQUISITION OF SUPPRESSION RATIOS

\begin{tabular}{lrrrc}
\hline Source & ss & df & ms & F \\
\hline Between subjects & 1.6995 & 31 & & \\
Test (A) (B) & 0.0823 & 1 & 0.0823 & 1.7496 \\
Training (B) & 0.3024 & 3 & 0.1008 & 2.1429 \\
AB & 0.1857 & 3 & 0.0619 & 1.3159 \\
Subj w. groups & 1.1291 & 24 & 0.0470 & \\
Within subjects & 11.6859 & 480 & & \\
Tria1s (C) & 5.1403 & 15 & 0.3426 & $26.1527 * *$ \\
AC & 0.1918 & 15 & 0.0128 & 0.9771 \\
BC ABC & 0.7122 & 45 & 0.0158 & 1.2061 \\
C x subj w. groups & 0.9207 & 45 & 0.0205 & $1.5649 *$ \\
\hline
\end{tabular}

\footnotetext{
$*_{p}<.05$

$* * p<.001$
} 
Table 4 reveals a significant trials (c) main effect. Since the focus of the study was upon the overall effects of interstimulus intervals, a formal internal analysis was not performed upon these groups by session differences. In order to interpret the significant three way $(A B C)$ interaction, separate analyses of sessions by test intervals were carried out on both the 3- and 30-second test groups. Each analysis consisted of a $4 \times 4$ analysis of variance with repeated measures on the trials variable, which was blocked into four 4-day groups for convenience of analysis. The means and standard deviations for the 3- and 30-second test intervals are presented in Tables 5 and 7 respectively. The results of the analysis for the 3-second test interval are presented in Table 6 , while the results for the 30-second test interval are presented in Table 8 .

TABLE 5

MEANS AND STANDARD DEVIATIONS OF SUPPRESSION RATIOS: 3-SECOND TEST GROUP

\begin{tabular}{cccc}
\hline Group & (Training-Test) & Mean & Standard Deviation \\
\hline 1 & $(1-3)$ & 0.0887 & 0.0656 \\
2 & $(3-3)$ & 0.0897 & 0.0585 \\
3 & $(7-3)$ & 0.1100 & 0.0672 \\
4 & $(30-3)$ & 0.1622 & 0.0860 \\
\hline
\end{tabular}

Inspection of Tables 6 and 8 reveals that the trials variable (B) is significant in both analyses. This indicates that suppression ratios changed significantly over trials. This observation is supported 
by inspection of Figures 1-8; in which suppression ratios are found to decrease rapidly during the first half of acquisition and then recover.

\section{TABLE 6}

ANALYSIS OF VARIANCE OF SUPPRESSION RATIOS: 3-SECOND TEST GROUP

\begin{tabular}{lcrcc}
\hline Source & ss & df & ms & F \\
\hline Between subjects & 2.0714 & 15 & & \\
Training (A) & 0.9239 & 3 & 0.3079 & 3.2207 \\
Subj w. groups & 1.1475 & 12 & 0.0956 & \\
Within subjects & 3.8729 & 48 & & \\
Trials (B) & 2.1323 & 3 & 0.7108 & $19.4248 *$ \\
AB x subj w. groups & 0.4233 & 9 & 0.0470 & 1.2855 \\
B x & 1.3173 & 36 & 0.0366 & \\
\hline
\end{tabular}

$*_{\mathrm{p}}<.001$

TABLE 7

MEANS AND STANDARD DEVIATIONS OF SUPPRESSION RATIOS: 30-SECOND TEST GROUP

\begin{tabular}{cccc}
\hline \hline Group & (Training-Test) & Mean & Standard Deviation \\
\hline 5 & $(1-30)$ & 0.1749 & 0.1263 \\
6 & $(3-30)$ & 0.0886 & 0.0687 \\
7 & $(7-30)$ & 0.1386 & 0.1179 \\
8 & $(30-30)$ & 0.1509 & 0.1205 \\
\hline
\end{tabular}

An analysis of the data contained in Tables 5 and 7 reveal that the assumption of homogeneity of variance was valid for both the 3 - and 30-second analyses (Hartley F-max for the 3 -second interval $=2.1613$, $\mathrm{df}=3, \mathrm{k}=4$; Hartley $\mathrm{F}-\max$ for 30 -second group $=3.18167, \mathrm{df}=3$, $k=4)$. 
TABLE 8

ANALYSIS OF VARIANCE OF SUPPRESSION RATIOS: 30-SECOND TEST GROUP

\begin{tabular}{lcrcc}
\hline \hline Source & ss & df & ms & F \\
\hline Between subjects & 4.3022 & 15 & & \\
Training (A) & 1.0296 & 3 & 0.3432 & 1.2585 \\
subj w. groups & 3.2726 & 12 & 0.2727 & \\
Within subjects & 9.2991 & 48 & & $10.1238 *$ \\
Trials (B) & 3.9880 & 3 & 1.3294 & 0.4941 \\
AB x Subj w. groups & 0.5839 & 9 & 0.0649 & \\
B x & 4.7271 & 36 & 0.1313 & \\
\hline
\end{tabular}

$*_{p}<.01$

Another way of examining the interaction is by visual inspection of the two group by trials graphs (Figures 9 and 10). Graphs of training and testing by trials are located in Appendix C. Inspection of Figures 9 and 10 reveals that for the 1-second training intervals suppression reaches a maximum in both the 3-and 30-second test intervals on the third block of trials. However, the 1-30 interval recovers less than the 1-3 interval by the fourth block of trials. Analysis of the 3-second training intervals indicates that the 3-3 interval reaches maximum suppression on the second block of trials, while the 3-30 reaches maximum suppression on the third block of trials. Both intervals show moderate recovery by the fourth block of trials, however, recovery is more abrupt in the 3-30 interval. In the 7-second training intervals a maximum suppression is reached for the 7-3 interval on the second block of trials, while in the 7-30 interval suppression is maximum on the third block of trials. Recovery is moderate 

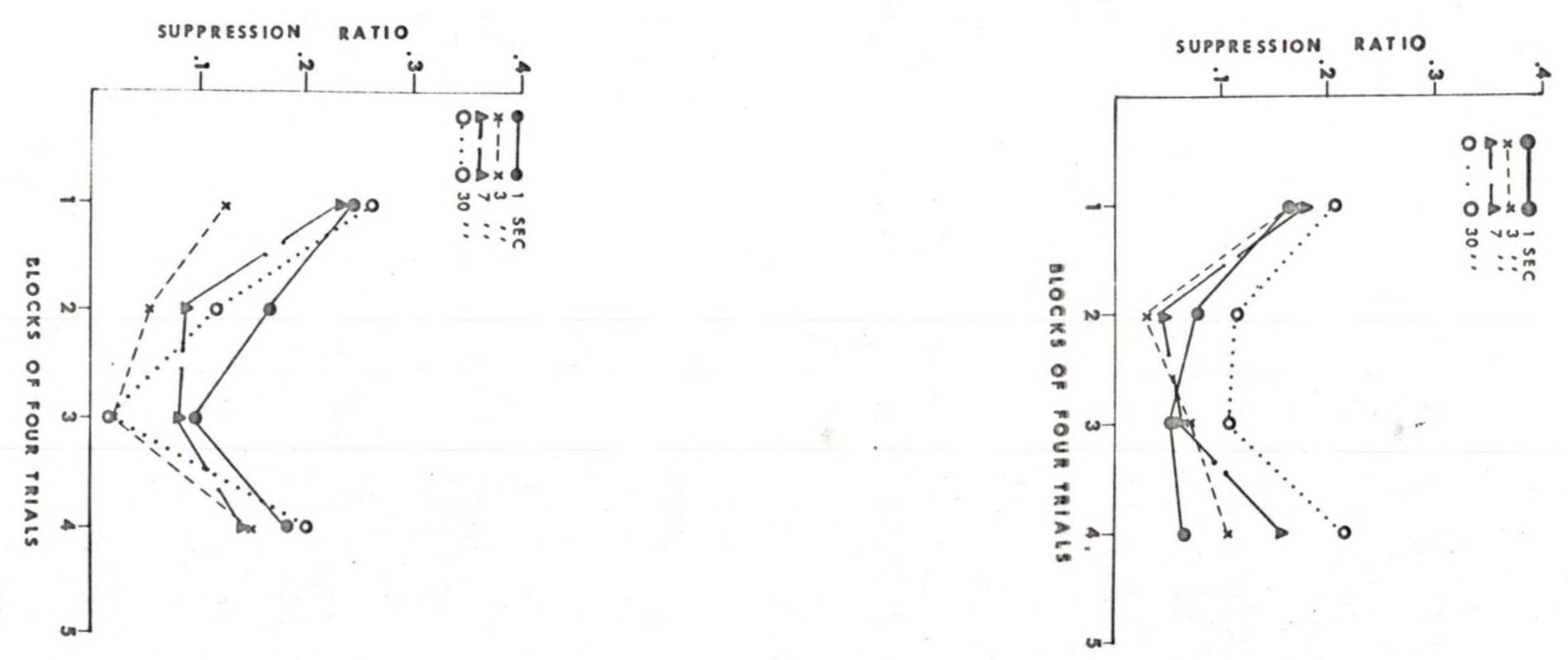
for both intervals by the fourth block of trials. Finally, suppression reaches a maximum on the third block of trials for both of the 30-second intervals. However, the 3-30 interval shows a greater recovery effect by the fourth block of trials.

Figure 11 presents group means for 3-and 30-second test conditions collapsed across all sessions for the various interstimulus interval values. Inspection of these means reveals no large differences in suppression between the two test intervals (e.g., two inversions of means and no significant training effects in Table 4). This is also evident from inspection of Figures 12-16, which show the development of suppression for the various CS-UCS intervals in the first five acquisition trials.

The 1-30 interval in Figure 11 shows less suppression than the other intervals. Inspection of group data for this interval (Appendix B) indicates that there is one deviant subject (S 7). For example, response suppression for S 7 required 12 sessions and recovered by trial 16 (the suppression ratio was 0.502), while the three other Ss required three to eight trials to suppress and by session 16 recovery was not complete (the suppression ratios ranged from a low of 0.000 to a high of 0.409 ). When this deviant $\mathrm{S}$ is removed from the $1-30$ group, the mean is reduced from 0.175 to 0.124 . Thus, the $1-30$ group mean is brought closer to the mean values of the other groups.

Following acquisition, the Ss received an extinction procedure in which the Ss were presented two 30-second CS trials with UCS omitted. Extinction was continued until the suppression ratios for each $S$ were equal to or greater than 0.450 for three out of the last four days. The number of trials to extinction were recorded and analyzed by a 



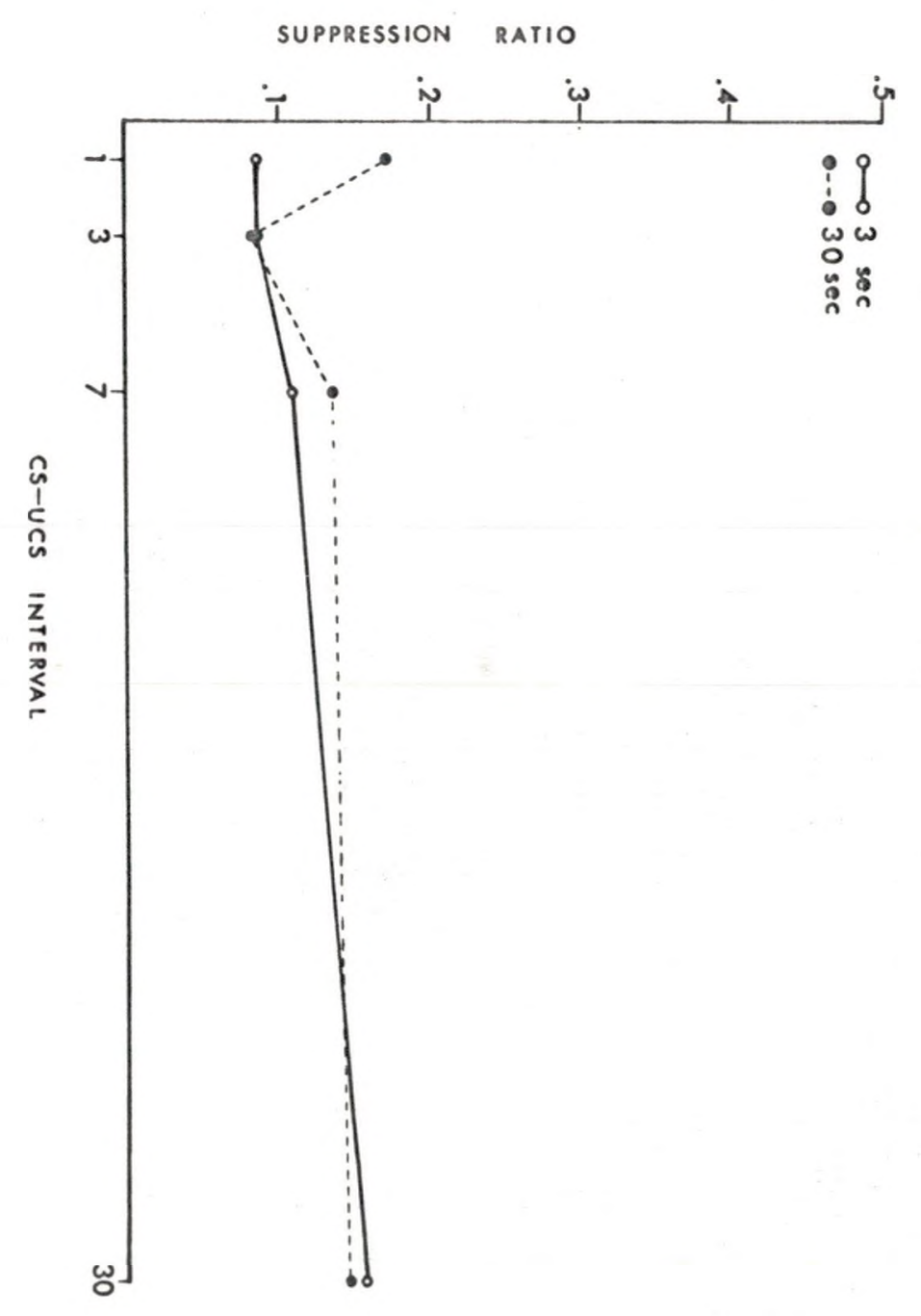




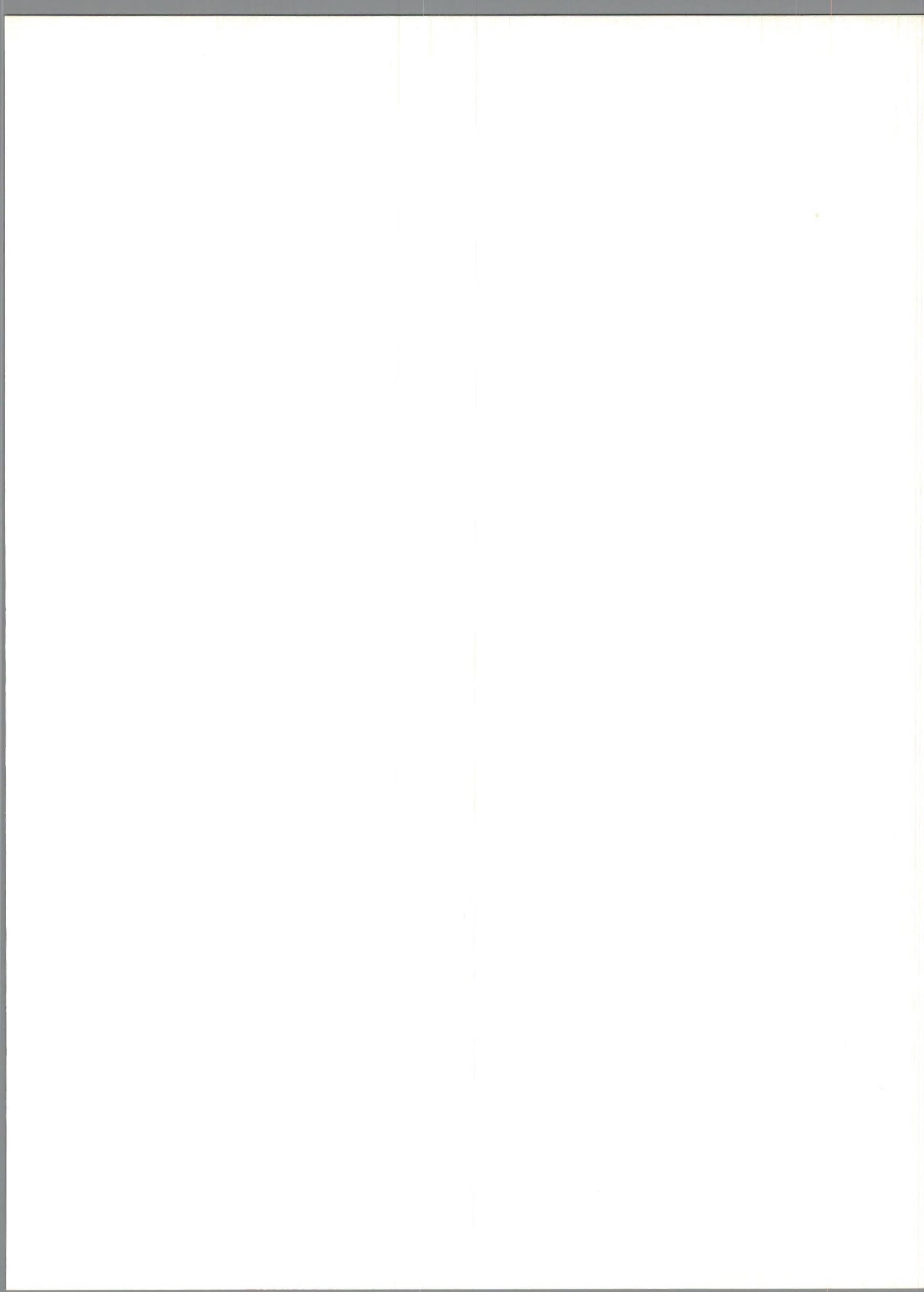




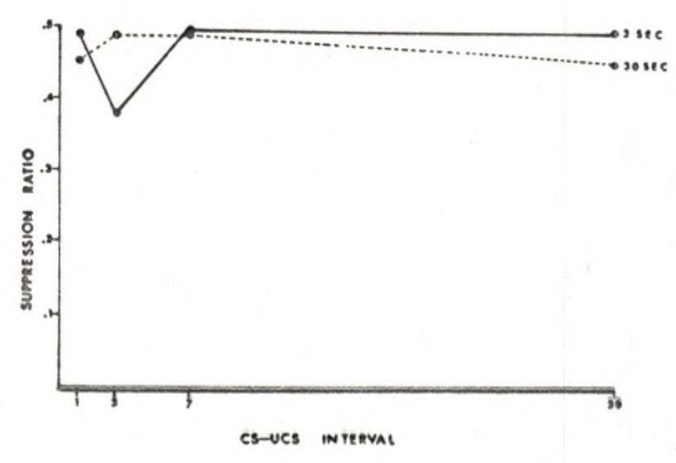

Fig. 12

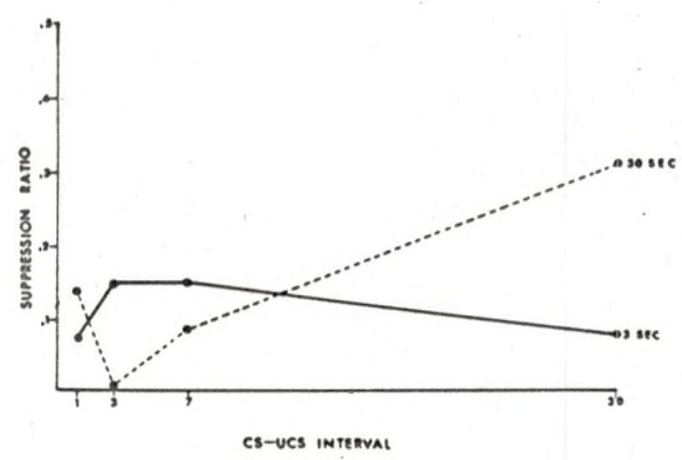

Fig. 14

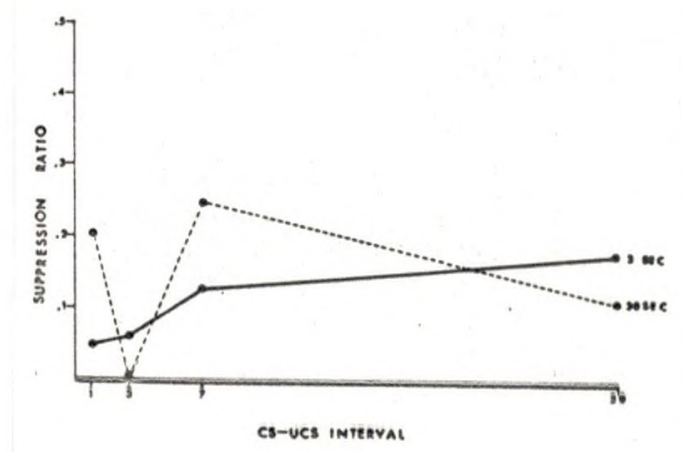

Fig. 13

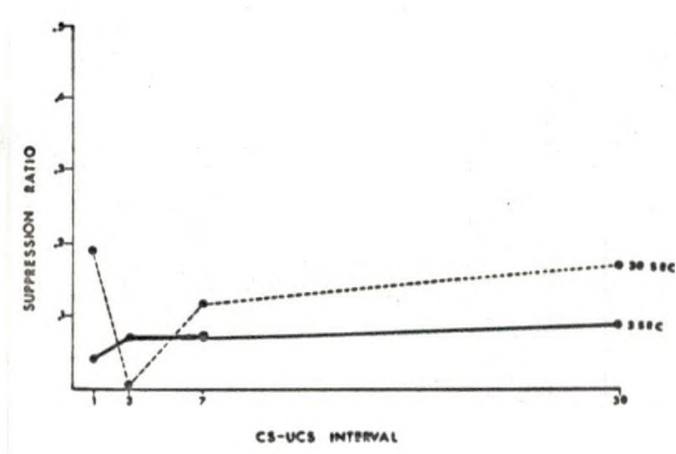

Fig. 15

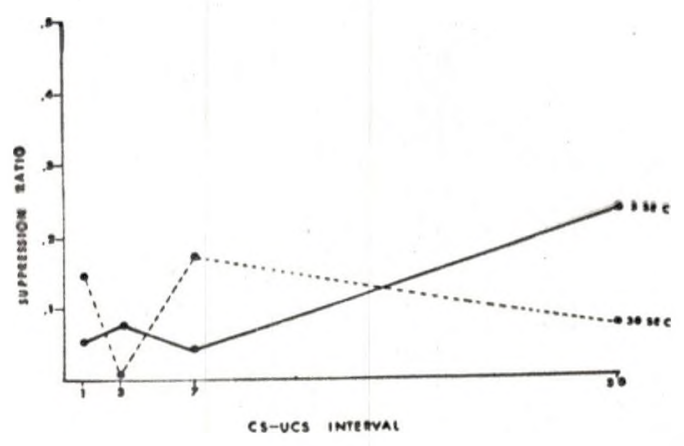

Fig. 16 
$2 \times 4$ analysis of variance, with two levels of test and four levels of training. The means and standard deviations are presented in Table 9 and the results of the analysis are summarized in Table 10. Inspection of Table 9 reveals that the assumption of homogeneity of variance was valid (Hartley $F-\max =4.9720$, df $=3, k=8$ ).

\section{TABLE 9}

MEANS AND STANDARD DEVIATIONS: EXTINCTION OF SUPPRESSION RATIOS

\begin{tabular}{cccc}
\hline Group & (Training-Test) & Mean & Standard Deviation \\
\hline 1 & $(1-3)$ & 6.50 & 2.6925 \\
2 & $(3-3)$ & 7.50 & 1.5000 \\
3 & $(7-3)$ & 7.00 & 2.1213 \\
4 & $(30-3)$ & 8.00 & 1.8708 \\
5 & $(1-30)$ & 7.50 & 3.3541 \\
6 & $(3-30)$ & 8.50 & 2.8722 \\
7 & $(7-30)$ & 10.25 & 2.5860 \\
8 & $(30-30)$ & 8.75 & 3.3447 \\
\hline
\end{tabular}

TABLE 10

ANALYSIS OF VARIANCE: EXTINCTION OF SUPPRESSION RATIOS

\begin{tabular}{lcccc}
\hline \hline Source & ss & df & ms & F \\
\hline Test (A) & 18 & 1 & 18 & 1.9681 \\
Training (B) & 12.25 & 3 & 4.0833 & 0.4455 \\
AB & 8.25 & 3 & 2.7500 & 0.3007 \\
Within cel1 & 219.50 & 24 & 9.1458 & \\
Total & 258.00 & 31 & & \\
\hline
\end{tabular}


Inspection of Table 9 indicates that the 30-second test groups were more resistant to extinction than the 3-second test groups. This effect may be due to the test interval values used in the present study. During extinction in the 30-second test interval, the $\mathrm{S}$ may continue to lick for a few seconds following CS onset. If the $S$ suppresses for several seconds and then begins licking again, the suppression ratios may be quite low. The 3-second test interval, however, may allow the $S$ to lick throughout the greater part of the interval before suppressing. Thus, the suppression ratios may assume higher values than those for the 30-second group.

Although the extinction data revealed no systematic interstimulus interval effects, spontaneous recovery for all groups is evident. Inspection of Figures 1-8 shows a decrease in the suppression ratios from the second test trial on day $N$ to the first test trial on day $N+1$. This observation is limited, however, by one reversal in the 3-3 interval, two reversals in the 30-3 interval, four reversals in the 1-30 interval, one reversal in the 3-30 interval, one reversal in the 7-30 interval, and two reversals in the 30-30 interval. 


\section{CHAPTER IV}

\section{DISCUSSION}

Research in the area of classical conditioning indicates that there is a range of interstimulus intervals at which conditioning is very effective. In the adult human these intervals range from 0.250 to 0.500 seconds for the major conditioned systems (e.g., GSR, finger withdrawal, and eyeblink conditioning) (Beecroft, 1966). However, very little has been done with the white rat in terms of classical conditioning. Boice and Denny (1965) employed the lick response in rats to investigate interstimulus intervals in a classical conditioning paradigm. The interstimulus intervals investigated were $0.5-$, 1-, 2-, 4-, and 6-seconds. In this study the rats were habituated to a water deprivation schedule. The Ss were placed in a "licker box" which contained a drinking well and a 10-watt light CS. The drinking well contained a no. 11 syringe needle which made available a small and constant quantity of water when the CS was presented. Thus the CS was present when the $S$ was licking. The Ss were run three hours per day for three days. Test trials were inserted on the average of one every 10 trials during these three days. "Anticipatory responses and test trial responses were scored as CRs if they occurred during the time of the CS-UCS interval or the CS duration, respectively, and were discriminatory in nature" (p. 93). Boice and 
Denny concluded that the two-second interstimulus interval was superior to the others tested.

Placement of an optimal interstimulus interval at two seconds (Boice and Denny, 1965) is controversial. Weisman (1965) found that a wide range of interstimulus intervals was effective in conditioning the lick response. In this study, rats were placed on a limited water access schedule. The Ss were then randomly assigned to either a contingent or a noncontingent group. The contingent Ss received responsecontingent water reinforcement on a FI 3 schedule. Reinforcement delivery for these noncontingent Ss was yoked to the FI 3 schedule. These Ss received response-independent reinforcement at the same time that the contingent Ss were reinforced. During the next phase, the contingent Ss were shifted to a discrete trials procedure in which each trial began with the onset of a light. The light remained on for 6-seconds. If the S licked the tube during the first 3-seconds, no reinforcement was delivered. However, if the S licked between the third and sixth seconds, reinforcement was delivered. Since the noncontingent Ss were yoked with the contingent Ss, they received training with a 3-second interstimulus interval and a 6-second overlapping CS. In order to evaluate the interstimulus interval effect, two contingent Ss were shifted to the noncontingent procedure and their rates were allowed to stabilize for six sessions with a 3-second interstimulus interval. Following response stabilization, the Ss were exposed to a 5-second interstimulus interval for two sessions, to a 10-second interstimulus interval for three sessions, to a 15-second interstimulus interval for two sessions, and to a 60-second interstimulus interval for three sessions. Calculation of the percentage of anticipatory lick responses 
for each interstimulus interval indicated that the 3-, 5-, 10-, and 15second intervals resulted in good conditioning, while the 60-second interval resulted in poor conditioning.

Although there are only two studies that have explicitly investigated interstimulus interval effects on the conditioned lick response, four other studies seem relevant to the discussion. These studies are concerned with the effects of various parameters upon conditioning in the lick response. However, since the studies employed a fixed interstimulus interval in their investigations, they are of interest. Patten and Deaux (1966) employed the lick response in an investigation of acquisition and extinction of conditioned responses. In this study a 3-second CS overlapped the UCS by 2-seconds. The control group consisted of CS-only presentations. The investigators found that conditioning occurred within 40 trials and reached a maximum after 70 trials. When investigating the orienting reflex during acquisition of the conditioned lick response, Patten and Rudy (1967a) employed a 3-second interstimulus interval in the experimental group. The control group consisted of random CS-UCS presentations. The investigators found that conditioning of the lick response occurred rapidly, making it comparable to the data obtained from the Patten and Deaux (1966) study. In the third relevant study, Patten and Rudy (1967b) employed a 3-second interstimulus interval while investigating lick conditioning in an omission training procedure (i.e., the experimental Ss received the UCS only if they did not lick the water tube during the three second interstimulus interva1). The results indicated that good conditioning occurred with the 3-second interstimulus interval. The final study of relevance was performed by DeBold, Miller, and Jensen (1965). In order to investigate 
the effect of drive strength on conditioning of the lick response, the investigators employed a 3-second CS duration while overlapped the UCS by 1 -second. The results indicated conditioning occurred in the high and medium drive groups.

In addition to research on interstimulus intervals in the conditioned lick response, data from heart rate conditioning is relevant to the problem of finding an optimal interstimulus interval. The heart rate studies are important because, like conditioned suppression, an aversive UCS is involved in conditioning. Black and Black (1967) explicitly investigated interstimulus interval effects on heart rate conditioning in the rat. The investigators used four interstimulus intervals (0.5-, 2.5-, 5-, 10-seconds) and a 5.5-second CS-only control group. Ss were randomly assigned to one of the five interstimulus interval groups and conditioning was begun. In a single day, Ss received 30 conditioning trials followed by 15 extinction trials. The EKG was recorded for 5-seconds prior to CS onset (40 db white noise) and for 20-seconds following CS onset. Heart rates were determined for each second in this period. The study indicated that conditioning was greater for the 2.5- and 5-second interstimulus intervals than for the 0.5 - or 10-second intervals.

Fitzgerald, Vandaris, and Brown (1966) conducted a study investigating the PRE in heart rate conditioning. In the study, a 5-second CS overlapped UCS by 1-second. One experimental group (E-100) received $100 \%$ reinforced trials, while the other experimental group (E-50) received $50 \%$ reinforced trials. A control group received random CS-UCS presentations. The results indicated that good conditioning occurred in the two experimental groups. Fehr and Stein (1965) reported a study 
in which an 8-second interstimulus interval was used to evaluate the development of heart rate changes in both acquisition and extinction. The data from acquisition indicated that conditioning occurred at this interstimulus interval value. Parrish (1967) used a 90-second interstimulus interval in a simultaneous discrimination procedure and found poor evidence for conditioned heart rate. Conditioned heart deceleration to the CS+ did not appear until the fourth and fifth sessions (6 CSt and 6 CS- trials per session). Finally, Tighe, Graves, and Riley (1968) found good conditioning with an 11-second CS which overlapped UCS by 1 second. The main purpose of the study was to investigate reversals in the simultaneous conditioning procedure.

In summary, the evidence for locating the optimal interstimuIus interval at a specific value for the rat is not conclusive. In the lick response, one study found that conditioning occurred most quickly at 2-seconds (Boice and Denny, 1965), while the other study found equally good conditioning at intervals of 3-, 5-, 10-, and 15seconds (Weisman, 1965). In the four other relevant studies, one used a 2-second interstimulus interval (DeBold, Miller, and Jensen, 1965), one used a 1-second interstimulus interval (Patten and Deaux, 1966), and two used a 3-second interval (Patten and Rudy, 1967a; Patten and Rudy, 1967b). However, further comparison between these four studies is not possible since they varied different conditioning parameters and used different criteria of conditioning. The results for heart rate conditioning do not clarify the situation. One study found an optimal interstimulus interval at 2.5 to 5 seconds (Black and Black, 1967). Several other studies found good heart rate conditioning at 4-seconds (Fitzgerald, Vandaris, and Brown, 1966), 
8-seconds (Fehr and Stein, 1965), and 10-seconds (Tighe, Graves, and Riley, 1968). Poor conditioning was found with a 90--econd interstimulus interval (Parrish, 1967).

The conditioning suppression paradigm bears a certain resemblance to that of classical conditioning (e.g., temporal relationships between CS and UCS). Consequently, it should be expected that conditioning would occur most quickly at some yet-to-be determined interstimulus interval.

Kamin (1965) indicated that conditioned suppression can be acquired at intervals in excess of 180-seconds for a delayed conditioning paradigm. Libby (1951) explicitly investigated several short duration CS-UCS intervals ranging from 0 to 30 seconds. He found that the amount of suppression increased with increases in the interstimulus intervals from 0 to 10 seconds. There are, however, several methodological problems associated with the study.

With a number of modifications, the present study attempted to replicate that of Libby (1951). These modifications involved the use of a consummatory lick response as an ongoing operant in a procedure similar to that of Estes and Skinner (1941). The analysis of variance, for both acquisition and extinction data, indicate that no differences exist between 1-, 3-, 7-, or 30-second interstimulus intervals in producing conditioned suppression. However, inspection of Figures 9 and 10 indicates certain regularities in the first two blocks of trials. For example, in block 1 of both the 3- and 30-second test intervals, the 3-second training interval results in lower suppression ratios than the other intervals. In the second block of trials, both test intervals, the suppression ratios for the 3-second interval are 
lowest, followed by the suppression ratios for the 7-second interval. These findings would appear to correspond to the classical conditioning of heart rate and licking, in which conditioning appears to be best within a range of 2 to 15 -seconds. It is possible, with a larger sample size, that the regularities observed in the present study would be significant. Nevertheless, no firm conclusions can be drawn from the present investigation in regard to optimal interstimulus intervals in conditioned suppression.

The differences between the present study and that of Libby (1951) probably are best accounted for by an analysis of the different methodologies employed. In acquisition Libby (1951) trained each $\mathrm{S}$ in a Mowrer "grill box." Acquisition consisted of three sessions in which each S received 10 pairings of a light CS and a shock UCS at the appropriate interstimulus interval. During the fourth session the Ss were trained to lever press on a CRF schedule. Lever press training continued for three sessions. The test phase consisted of (1) 10-minutes of CRF in the absence of 1ight, (2) 10-minutes of CRF in the presence of light, or (3) 25-minutes of CRF in the absence of light. During the test phase, all lever presses were reinforced with food. Libby's (1951) acquisition and test procedure are unnecessarily complex and seldom observed in the present literature. In acquisition the shock presentations were massed. The procedure involved in testing for suppression employed a shock extinction procedure. The CS presentations were no longer paired with UCS. Thus, the acquisition of conditioned suppression can not be followed across sessions. The Estes and Skinner (1941) procedure employed in the present study, allows the assessment of suppression in a continued shock reinforcement procedure. The CS 
and UCS are paired throughout acquisition. The present procedure also allows the assessment of conditioned suppression across trials. In addition, the shock presentations in the present study were distributed, not massed.

The use of a test interval procedure may be another explanation for failure to find significant training effects. Brookshire (1970), in a review of quantitative differences in conditioning, states that it is unclear whether interstimulus intervals should be evaluated by determining the frequency of occurrence for the conditioned response in each CS-UCS training trial or by presenting Ss with CS-only test trials that are equal in length regardless of interstimulus interval. The former procedure seems to be better because it describes ". . . for comparative purposes, the conditions under which learning is most effectively demonstrated during ordinary acquisition trials" (p. 311). The disadvantages with the latter procedure is that it ". . . tends to favor long-latency CRs, and it favors CRs to those CSs for which CSonset is not a very distinctive cue" (p. 3-1). Thus, it is possible that the results of the present study would have been different had a procedure been employed in which interstimulus intervals were evaluated in each CS-UCS training trial.

In summary, the free operant procedure of Estes and Skinner (1941) has shown superiority in investigations of various parameters of conditioned suppression (e.g., CS intensity, UCS intensity, partial reinforcement, etc.). The "grill box" procedure has not been used in any parametric investigations of conditioned suppression. The present study employed an operant standardized by James and Mostoway (1968), Burdick and James (1970), and Yashida, Kai, and Imada (1969) in a 
paradigm standardized by Estes and Skinner (1941) and Kamin (1961, 1965). These methodological differences between the present study and that of Libby (1951) are probably sufficient to account for the observed discrepancies.

Several other relationships were indicated from the data in the present study. Inspection of the acquisition curves, Figures 1-8, indicate rapid conditioning for all groups. For example, all groups reached a minimum in suppression ratios by trial 14 . Inspection of acquisition Figures 1-8 indicates a $U$ shaped acquisition curve for all groups. During the last three to eight sessions, the suppression ratios increased for all groups. This is similar to the $U$ shaped acquisition curves found by Annau and Kamin (1961) for the 0.49-mA group and for all groups in the James and Mostoway study (1968). The shape of the acquisition curve is probably due to UCS intensity effects. In a conditioned suppression procedure that uses the bar press as an operant, a U shaped curve is found only with low and moderate intensity shocks (Annau and Kamin, 1961; Hendry and Van-Toller, 1967; and Millenson and Hendry, 1965). However, in conditioned suppression employing the lick response as an operant, U shaped acquisition curves are found high shock intensities up to 2.0-mA (James and Mostoway, 1968). This may indicate that UCS intensity effects consummatory and skeletal operants differently. 
A.PPENDIX A 
TABLE 11

SUPPRESSION RATIOS FOR EACH SUBJECT FOR HABITUATION DAYS

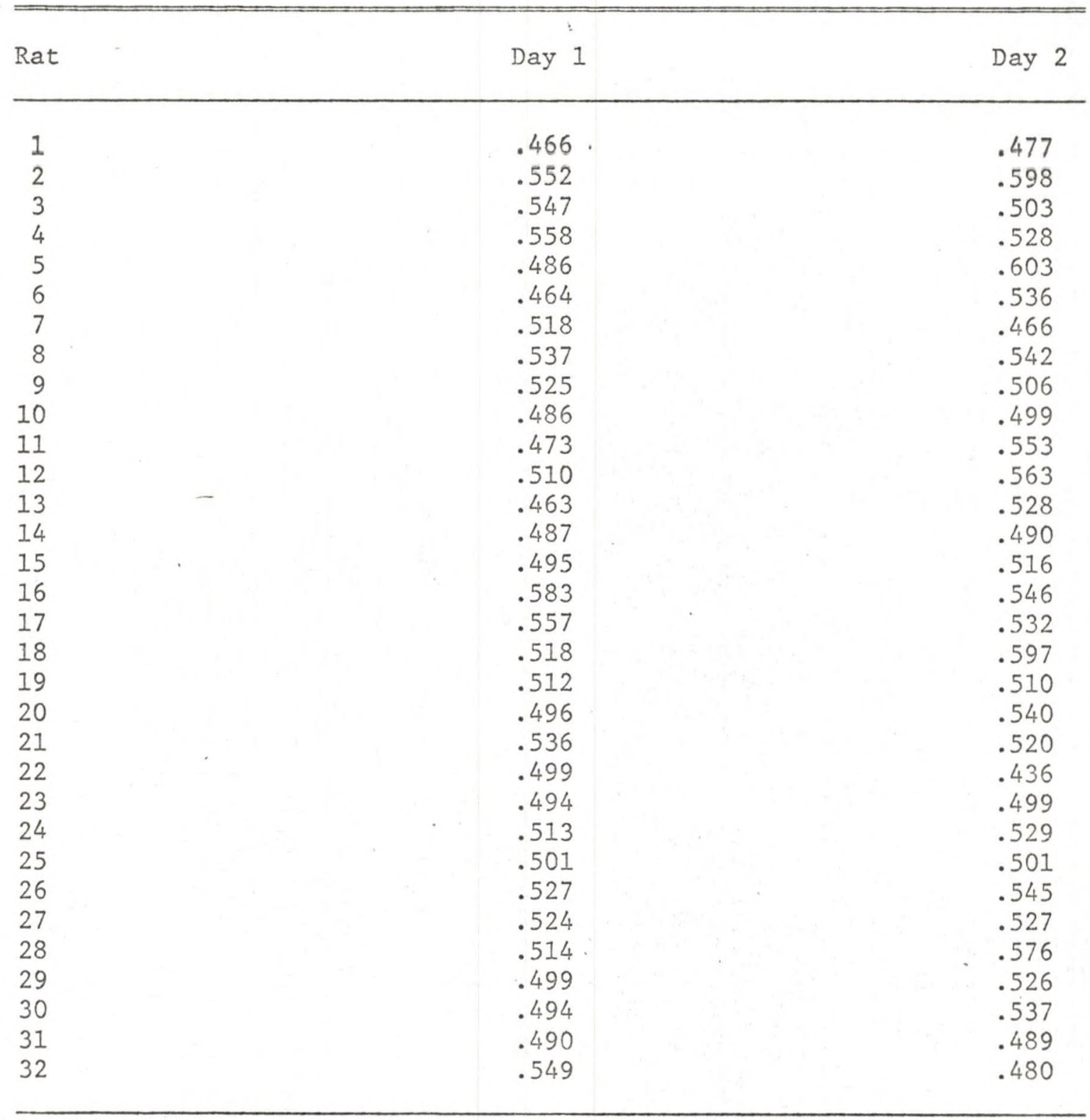


APPENDIX B 
TABLE 12

SUPPRESSION RATIOS FOR EACH SUBJECT FOR ACQUISITION AND EXTINCTION

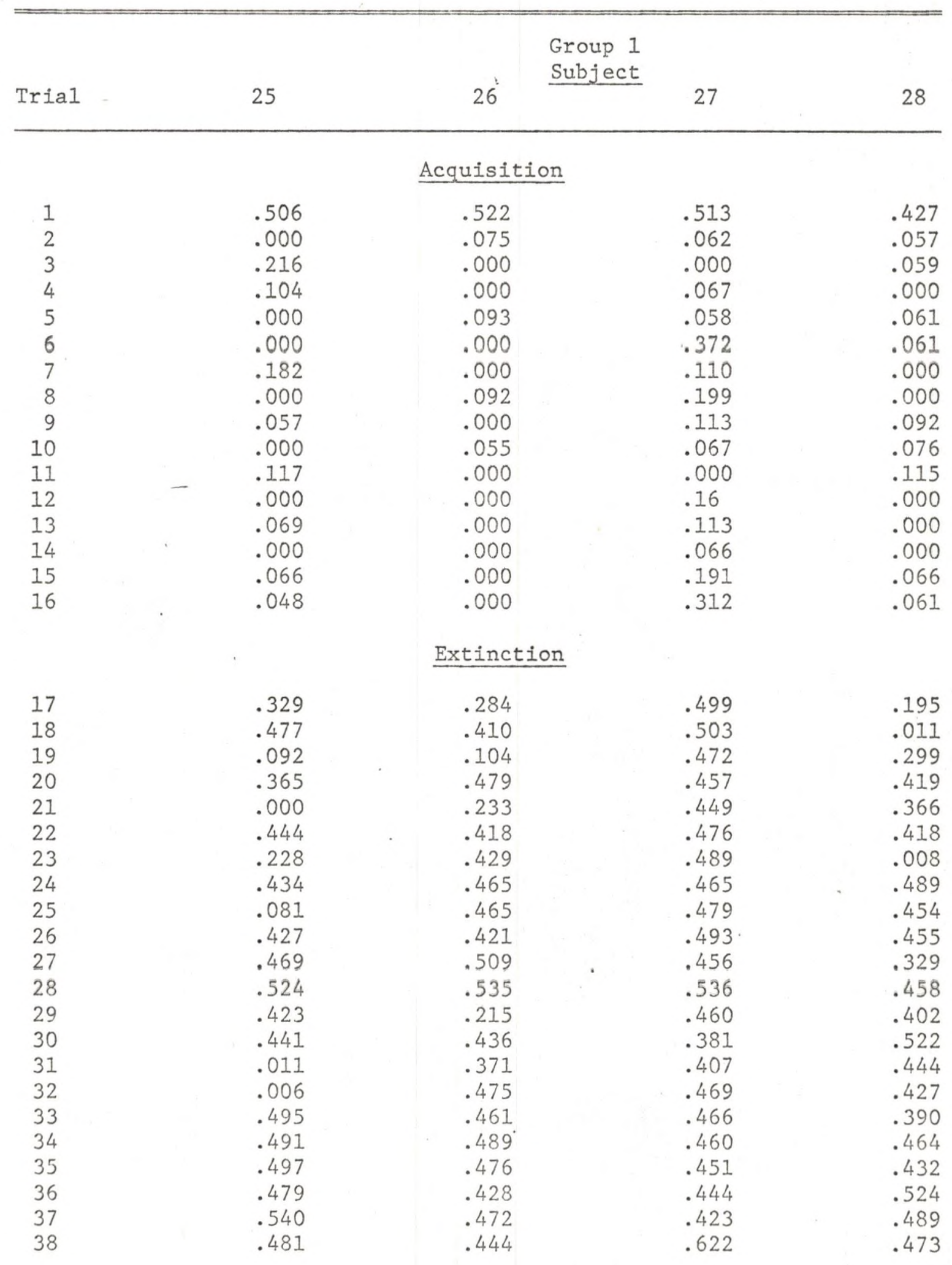


TABLE 12--Continued

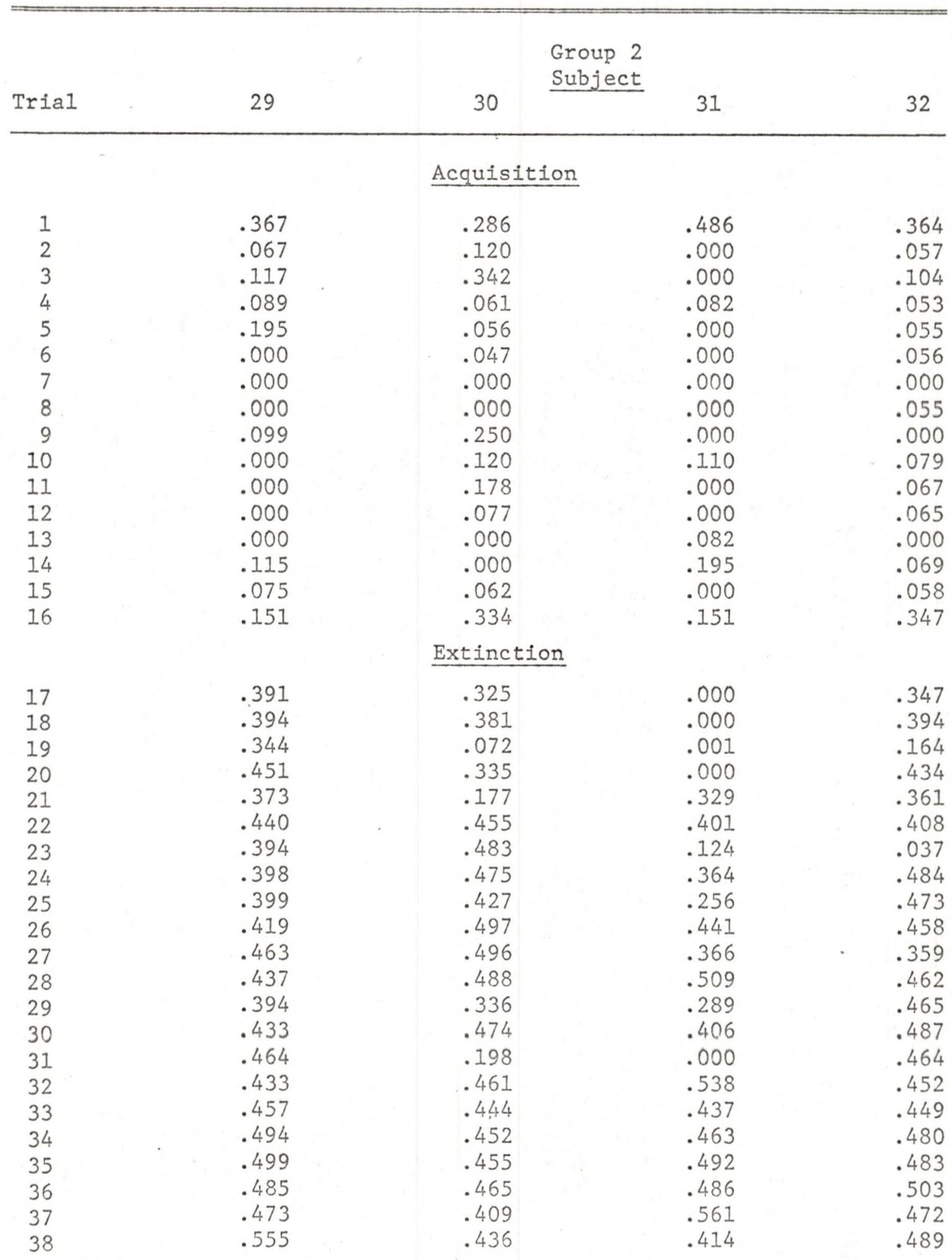


TABLE 12--Continued

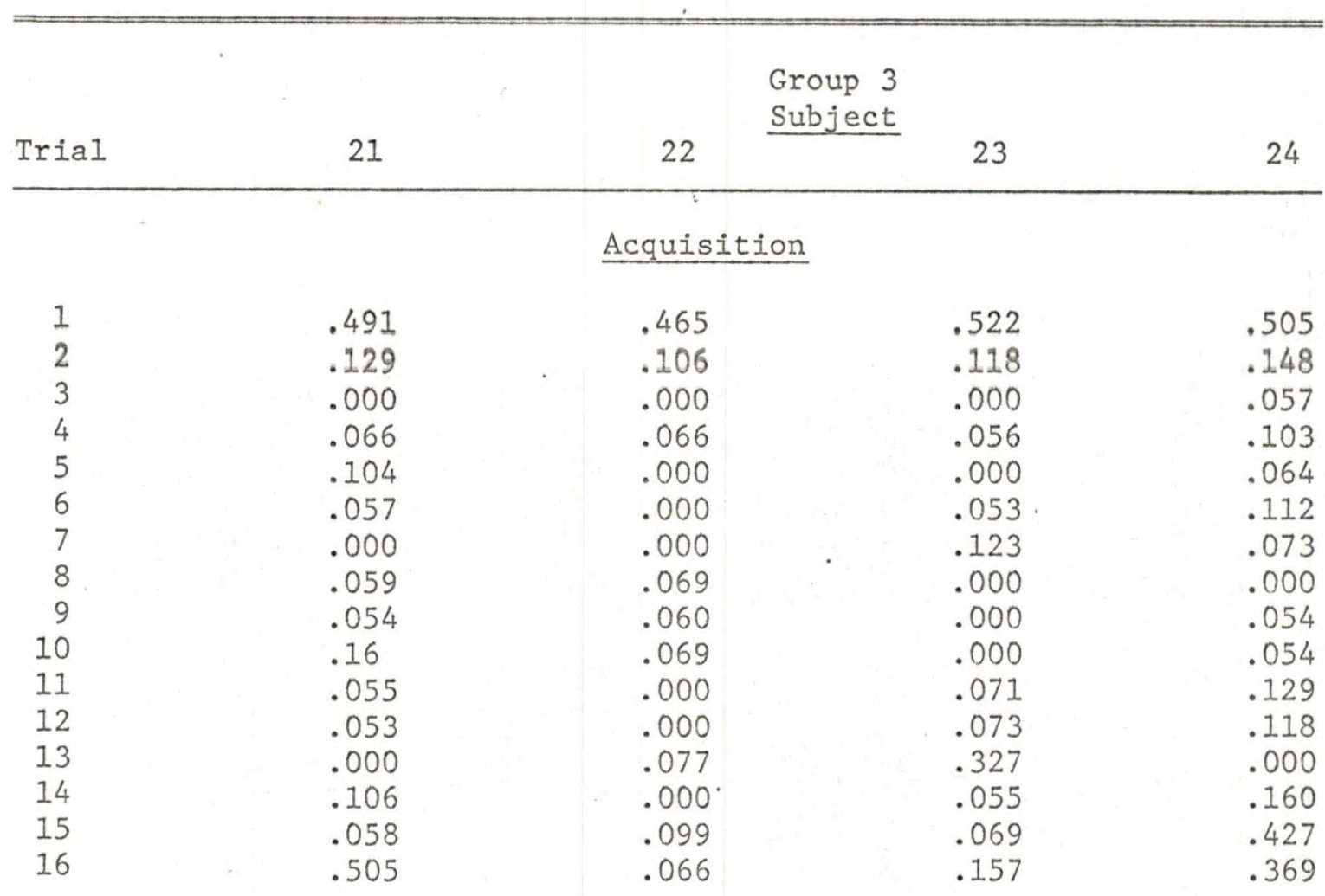

Extinction

$\begin{array}{ll}17 & .203 \\ 18 & .226 \\ 19 & .484 \\ 20 & .342 \\ 21 & .228 \\ 22 & .397 \\ 23 & .374 \\ 24 & .473 \\ 25 & .371 \\ 26 & .398 \\ 27 & .435 \\ 28 & .481 \\ 29 & .375 \\ 30 & .499 \\ 31 & .441 \\ 32 & .487 \\ 33 & .472 \\ 34 & .516 \\ 35 & .50 \\ 36 & .498 \\ 37 & .473 \\ 38 & .488\end{array}$

.007
.474
.072
.205
.286
.178
.129
.405
.276
.436
.163
.444
.107
.450
.262
.400
.311
.492
.359
.498
.480
.421

.006

.309

.448

.320

.006

.507

.489

.496

.469

.321

.345

.376

.159

.446

.484

.498

.356

.513

.467

.450

.373

.482

.464

.281

.536

.475

.542

.471

.625

.516

.474

.478

.503

.497

.476

.485

.533

.466

.497 
TABLE 12--Continued

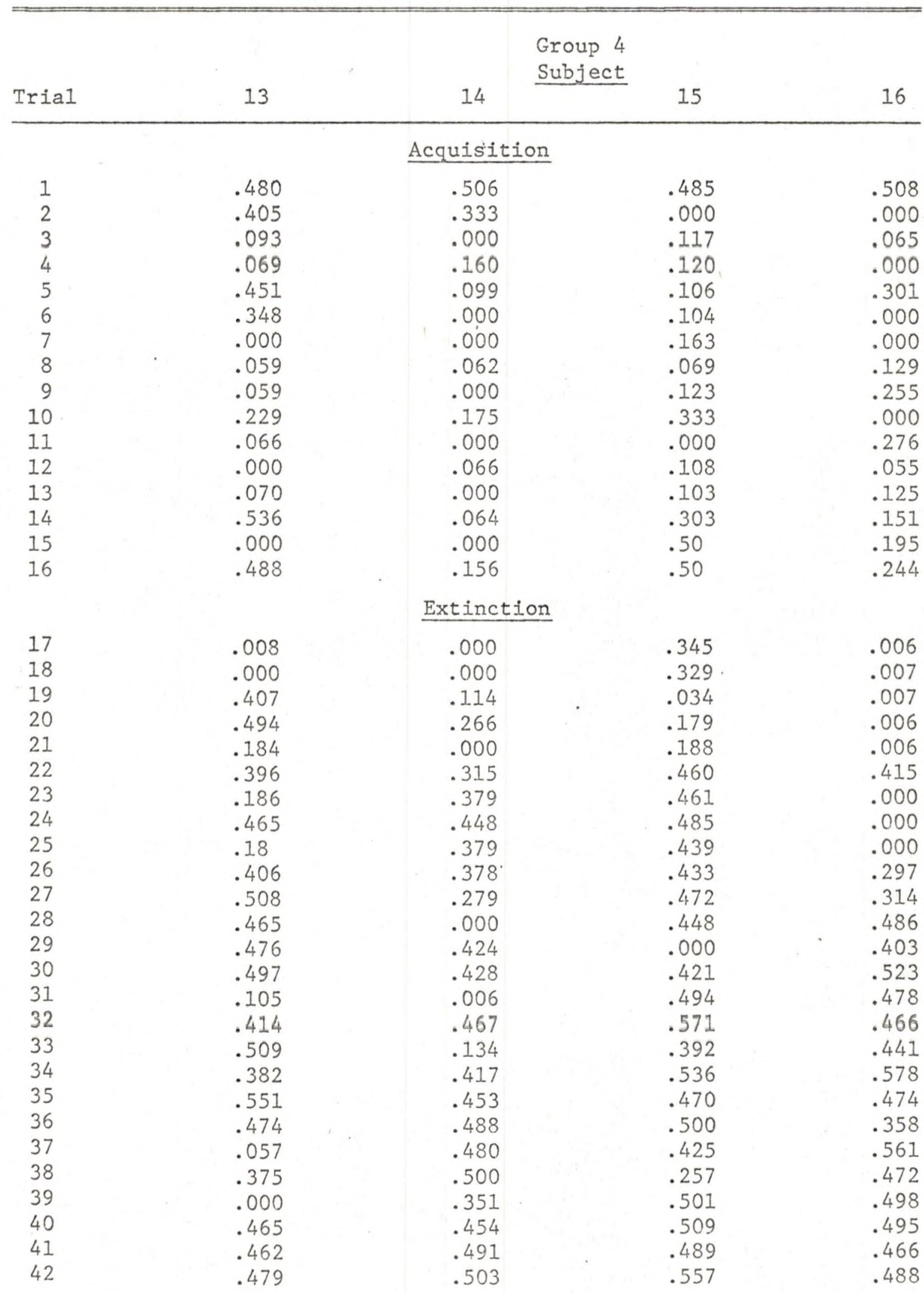


TABLE 12--Continued

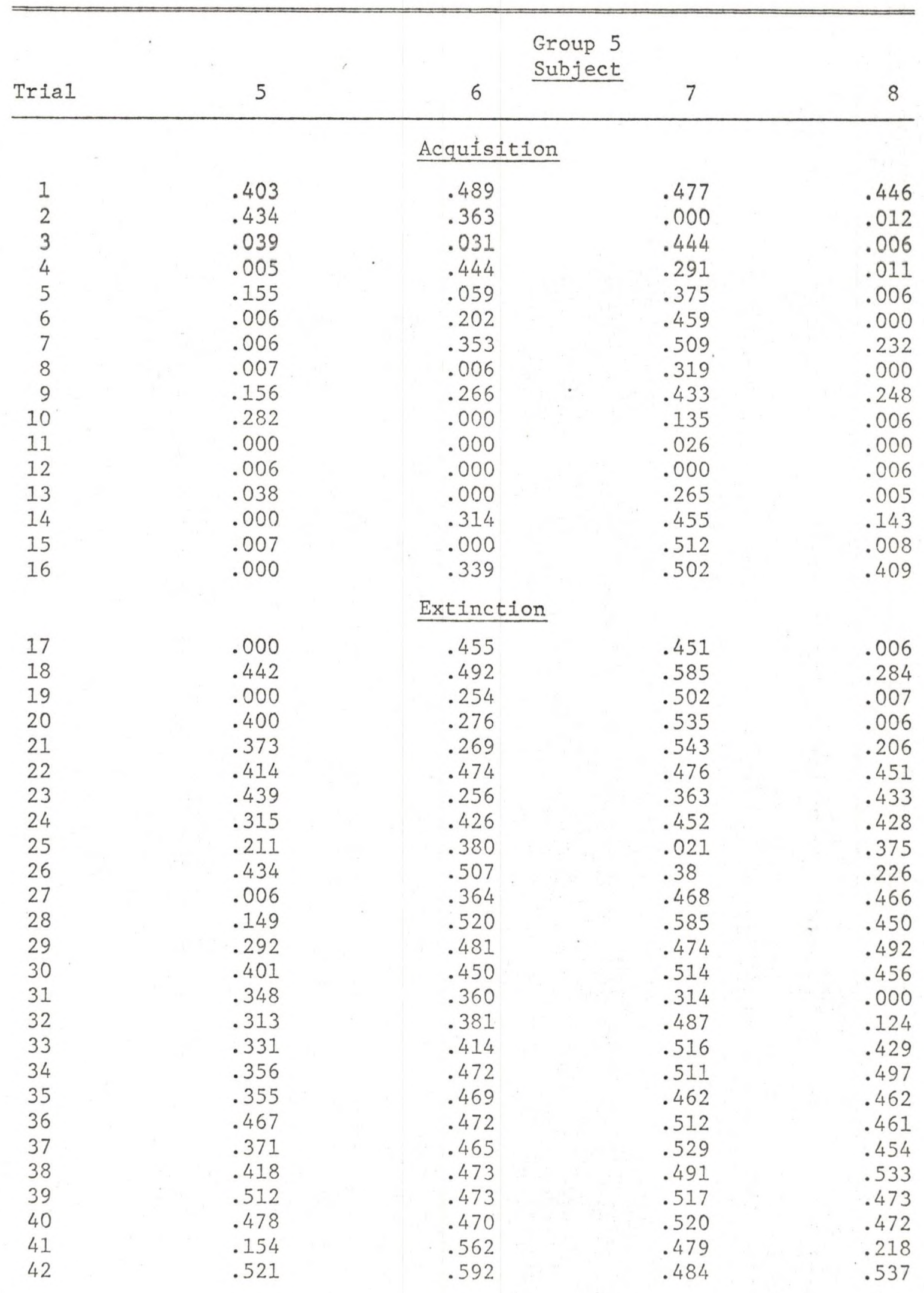


TABLE 12--Continued.

\begin{tabular}{|c|c|c|c|c|}
\hline Trial & 17 & 18 & $\begin{array}{l}\text { Group } 6 \\
\text { Subject } \\
\end{array}$ & 20 \\
\hline \multicolumn{5}{|c|}{ Acquisition } \\
\hline 1 & .487 & .554 & .418 & .493 \\
\hline 2 & .000 & .000 & .006 & .011 \\
\hline 3 & .000 & .006 & .006 & .006 \\
\hline 4 & .007 & .009 & .007 & .000 \\
\hline 5 & .018 & .009 & .007 & .005 \\
\hline 6 & .011 & .112 & .006 & .134 \\
\hline 7 & .000 & .000 & .098 & .262 \\
\hline 8 & .000 & .006 & .000 & .004 \\
\hline 9. & .000 & .006 & .000 & .004 \\
\hline 10 & .000 & .015 & .000 & .126 \\
\hline 11 & .000 & .000 & .114 & .006 \\
\hline 12 & .006 & .008 & .000 & .046 \\
\hline 13 & .363 & .010 & .184 & .345 \\
\hline 14 & .443 & .013 & .006 & .000 \\
\hline 15 & .021 & .000 & .000 & .156 \\
\hline 16 & .000 & .460 & .006 & .449 \\
\hline
\end{tabular}

\section{Extinction}

$\begin{array}{lllll}17 & .411 & .000 & .007 & .500 \\ 18 & .453 & .024 & .230 & .494 \\ 19 & .000 & .000 & .000 & .000 \\ 20 & .473 & .011 & .000 & .400 \\ 21 & .006 & .000 & .000 & .028 \\ 22 & .439 & .000 & .227 & .426 \\ 23 & .317 & .008 & .289 & .055 \\ 24 & .478 & .261 & .326 & .407 \\ 25 & .023 & .400 & .191 & .267 \\ 26 & .383 & .444 & .477 & .405 \\ 27 & .263 & .274 & .363 & .448 \\ 28 & .503 & .484 & .460 & .492 \\ 29 & .006 & .000 & .278 & .468 \\ 30 & .262 & .402 & .417 & .467 \\ 31 & .306 & .366 & .449 & .377 \\ 32 & .517 & .306 & .397 & .521 \\ 33 & .404 & .401 & .369 & .418 \\ 34 & .474 & .491 & .457 & .506 \\ 35 & .472 & .471 & .471 & .533 \\ 36 & .499 & .437 & .479 & .432 \\ 37 & .353 & .452 & .527 & .491\end{array}$


TABLE 12--Continued

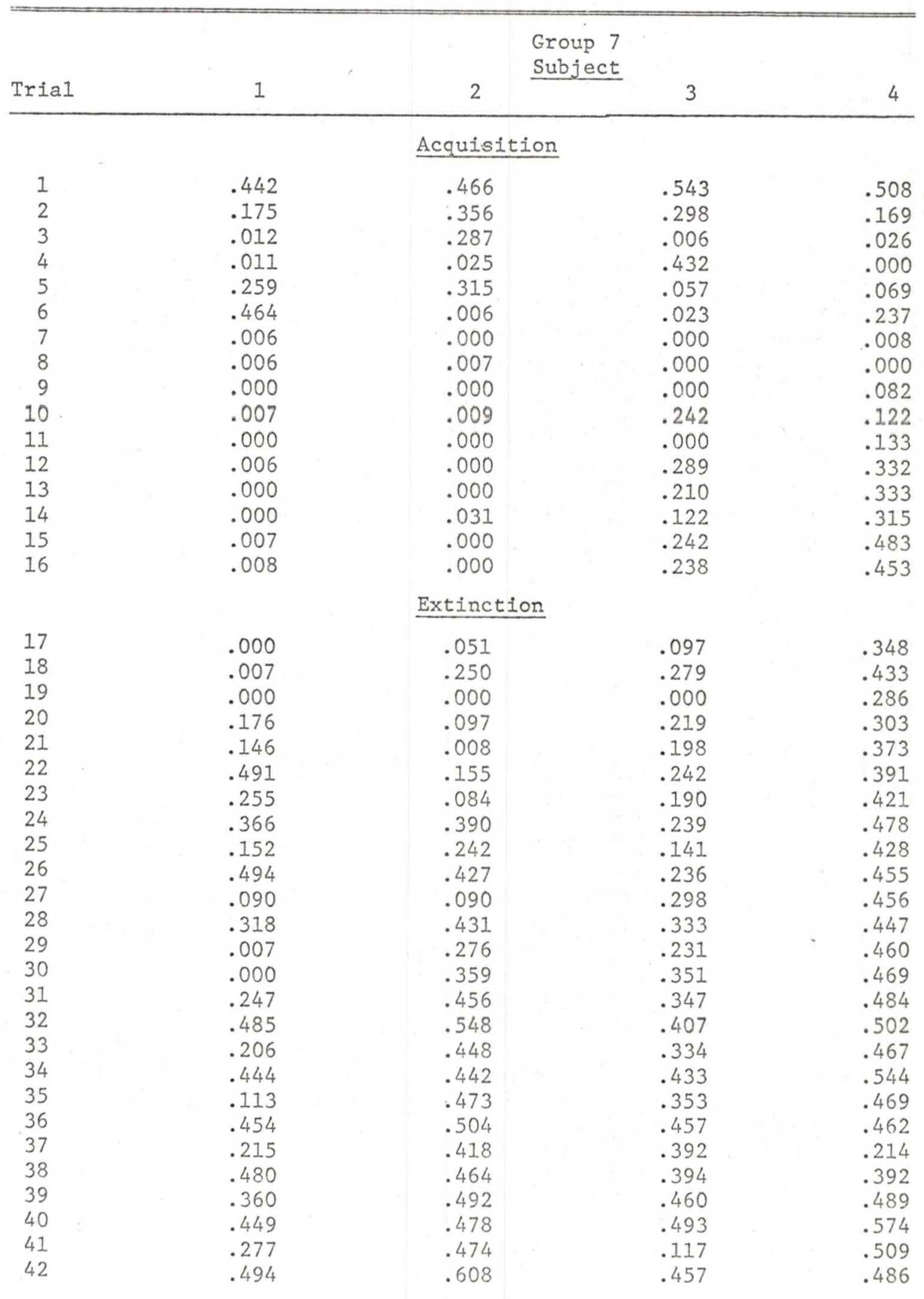


TABLE 12--Continued

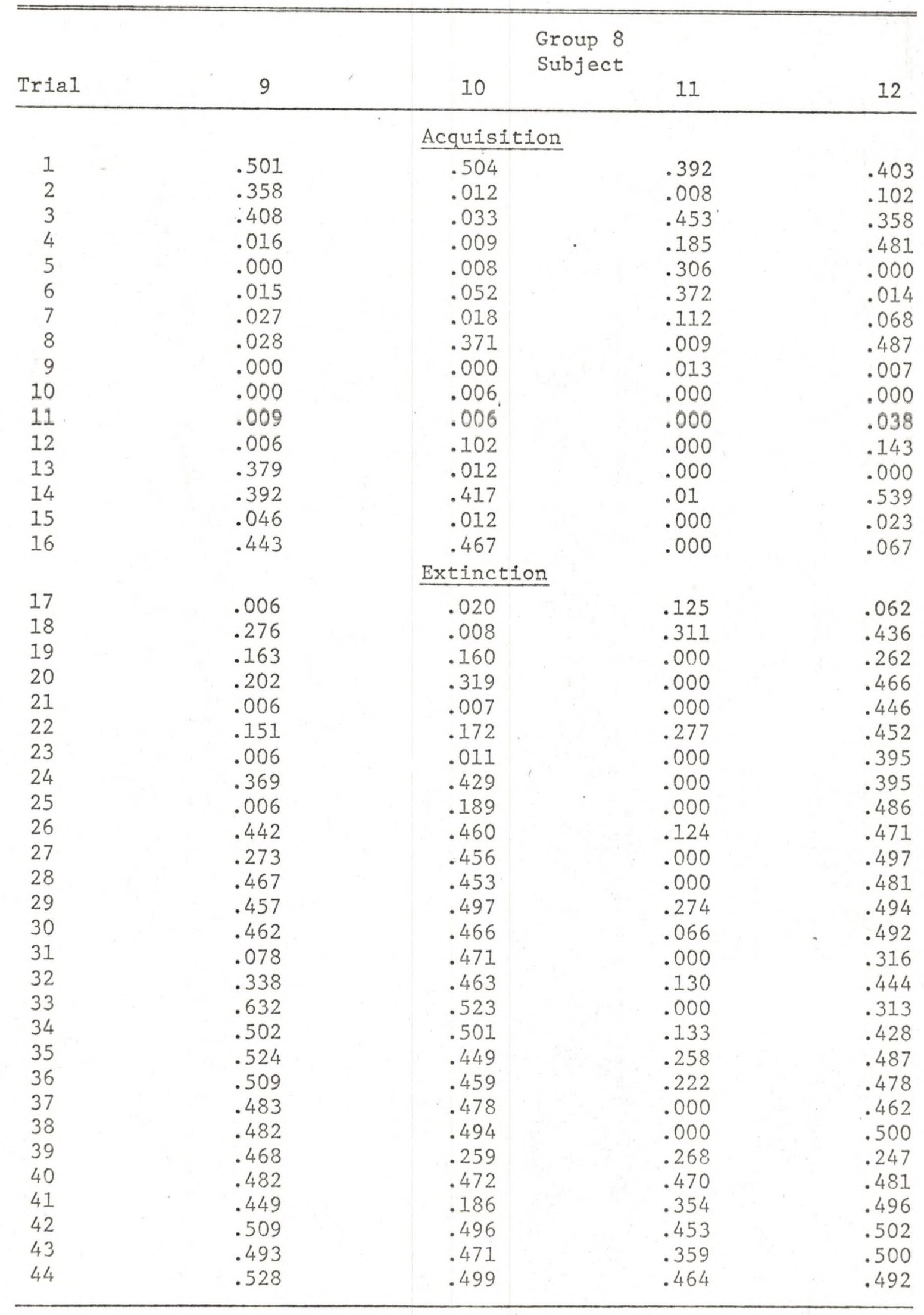


APPENDIX C 


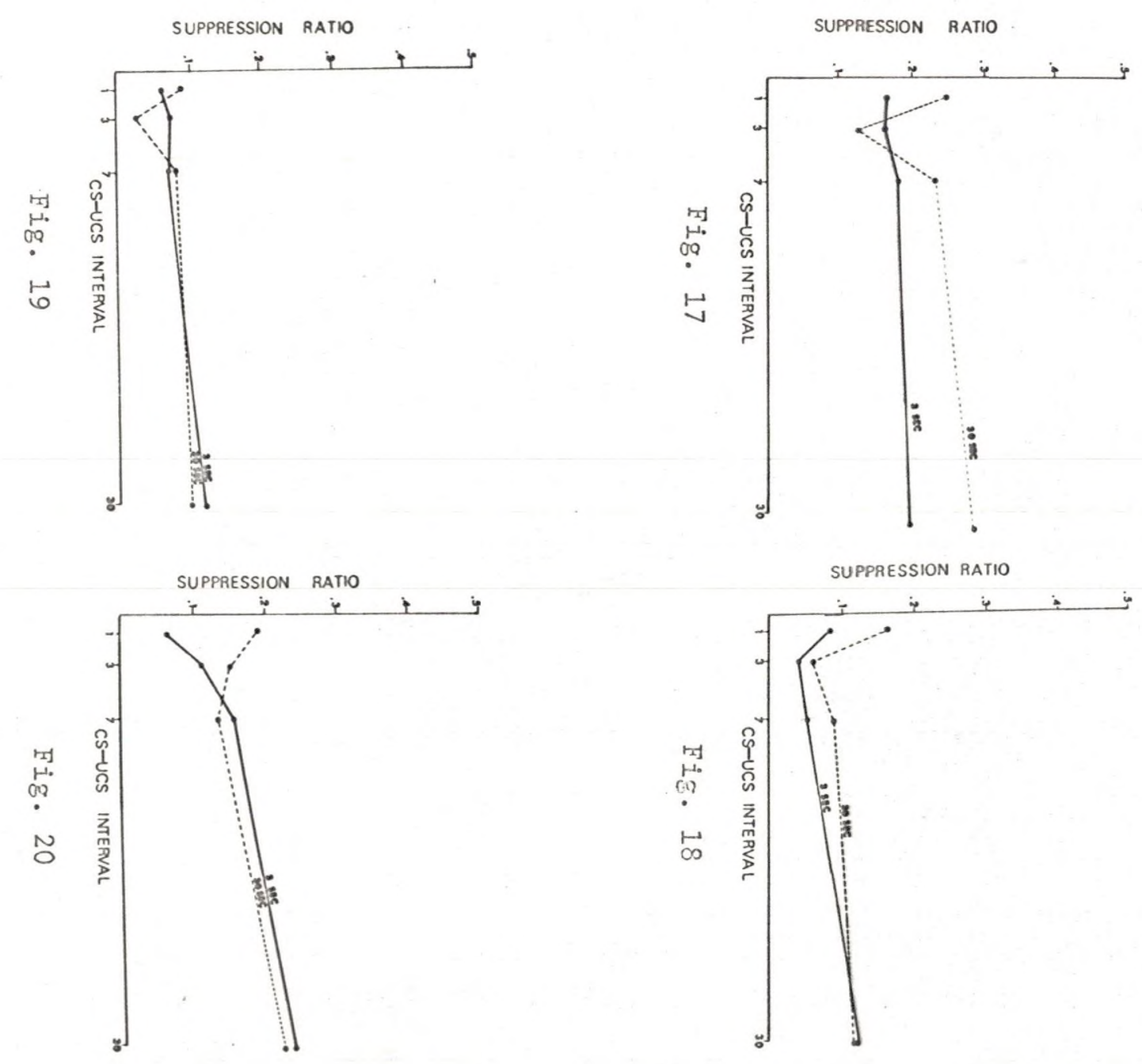
REFERENCES 
Annau, Z., \& Kamin, L. J. The conditioned emotional response as a function of intensity of the US. Journal of Comparative and Physiological Psychology, 1961, 54, 428-432.

Ayres, J. J. Conditioned suppression and the information hypothesis. Journal of Comparative and Physiological Psychology, 1966, $\underline{62,21-25 .}$

Azrin, N. H. Some effects of two-intermittent schedules of immediate and non-immediate punishment. Journal of Psychology, 1956, 42, $3-21$.

Beecroft, R. S. Classical conditioning. California: Psychonomic Press, 1966.

Beecroft, R. S. Emotional conditioning. Psychonomic Science, 1967, 2, (Whole number 20).

Black, R. W., \& Black, P. E. Heart rate conditioning as a function of interstimulus interval in rats. Psychonomic Science, 1967, 8 , 219-220.

Blackman, D. L. Response rate and conditioned suppression. Psychologica1 Reports, 1966, 19, 687-693.

Boice, R., \& Denny, M. R. The conditioned licking response in rats as a function of CS-UCS interval. Psychonomic Science, 1965, 3 , 93-94.

Brady, J. V. The extinction of a conditioned "fear" response as a function of reinforcement schedules for competing behavior. Journal of Psychology, 1955, 40, 25-34.

Brady, J. V., \& Hunt, H. F. An experimental approach to the analysis of emotional behavior. Journal of Psychology, 1955, 40, 313-324.

Brady, J. V., \& Conrad, D. G. Some effects of limbic system selfstimulation upon conditioned emotional behavior. Journal of Comparative and Physiological Psychology, 1960, 53, 128-137.

Brimer, C. J., \& Dockrill, F. J. Partial reinforcement and the CER. Psychonomic Science, 1966, 5, 185-186. 
Brookshire, K. H. Comparative psychology of learning. In M. H. Marx (Ed.), Learning: Interactions. London: Macmillan Co., 1970.

Burdick, C. K., \& James, J. P. Spontaneous recovery of conditioned suppression of licking by rats. Journal of Comparative and Physiological Psychology, 1970, $\underline{72}, 467-470$.

Carlton, P. L., \& Didamo, P. Some notes on the control of conditioned suppression. Journal of the Experimental Analysis of Behavior, $1960, \underline{3}, 255-258$.

Church, R. M., Wooten, C. L., \& Matthews, T. J. Discriminative punishment and the conditioned emotional response. Learning and Motivation, 1970, 1, 1-17.

Coleman, J. C. Abnormal psychology and modern life. Chicago: Scott, Foresman, and Company, 1964.

Davenport, J. W. Higher-order conditioning of fear (CER). Psychonomic Science, 1966,4 , 27-28.

DeBold, R. C., Miller, N. E., \& Jensen, D. D. Effect of strength of drive determined by a new technique for appetitive classical conditioning in rats. Journal of Comparative and Physiological Psychology, 1965, 59, 102-108.

Desiderato, 0. Generalization of conditioned suppression. Journal of Comparative and Physiological Psychology, 1964, 57, 434-437.

Dyal, J. A., \& Goodman, E. D. Fear conditioning as a function of CS duration during acquisition and suppression tests. Psychonomic Science, 1966, 4, 249-250.

Eggar, M. D., \& Miller, N. E. Secondary reinforcement in rats as a function of information value and reliability of the stimulus. Journal of Experimental Psychology, 1962, 64, 97-104.

Estes, W. K., \& Skinner, B. F. Some quantitative properties of anxiety. Journal of Experimental Psychology, 1941, 29, 390-400.

Fehr, I. S., \& Stein, J. A. Heart-rate conditioning in the rat. Journal of Psychomatic Research, 1965, $8,441-453$.

Fitzgerald, R. D., Vandaris, R. M., \& Brown, J. S. Classical conditioning of heart-rate deceleration in the rat with continuous and partial reinforcement. Psychonomic Science, 1966, 6, 437-438.

Geller, I. Conditioned "anxiety" and punishment effects on operant behavior in goldfish (Carassius auratus). Science, 1963, 141, $351-353$.

Geller, I. Conditioned suppression in goldfish as a function of shockreinforcement schedule. Journal of the Experimental Analysis of Behavior, $1964, \underline{7}, 345-350$. 
Hammond, L. J. Increased responding CS- in differential CER. Psychonomic Science, $1966, \underline{5}, 337-338$.

Hanfmann, E. Psychological approaches to the study of anxiety. In P. W. Hock and J. Zubin (Eds.), Anxiety. New York: Grune and Stratton, 1950. Pp. 51-70.

Hendry, D. P., \& Van-Toller, C. Alleviation of conditioned suppression. Journal of Comparative and Physiological Psychology, 1965, 59, 458-460.

Hoffman, H. S., \& Fleshler, M. Stimulus factors in aversive controls: The generalization of conditioned suppression. Journal of the Experimenta1 Analysis of Behavior, 1961, 4, 371-378.

Hunt, H. F., \& Otis, L. S. Conditioned and unconditioned emotional defecation in the rat. Journal of Comparative and Physiological Psychology, 1953, 46, 378-382.

Hunt, H. F., \& Brady, J. V. Some effects of punishment and intercurrent anxiety on a simple operant. Journal of Comparative and Physiological Psychology, 1955, 48, 305-310.

James, J. P., \& Mostoway, W. W. Conditioned suppression of licking as a function of shock intensity. Psychonomic Science, 1968, 13, $161-162$.

Kamin, L. J. Trace conditioning of the conditioned emotional response. Journal of Comparative and Physiological Psychology, 1961, 54, 149-153.

Kamin, L. J., \& Brimer, C. J. The effects of intensity of conditioned and unconditioned stimuli on a conditioned emotional response. Canadian Journal of Psychology, 1963, 17, 194-198.

Kamin, L. J., \& Schaub, R. E. Effects of conditioned stimulus intensity on the conditioned emotional response. Journal of Comparative and Physiological Psychology, 1963, 56, 502-507.

Kamin, L. J. Temporal and intensity characteristics of the conditioned stimulus. In W. F. Prokasy (Ed.), Classical Conditioning. New York: Appleton-Century-Crofts, 1965. Pp. 118-147.

Libby, A. Two variables in the acquisition of depressant properties of a stimulus. Journal of Experimental Psychology, 1951, 42, 100-107.

Lindsley, O. R., \& Jetter, W. W. The temporary elimination of discrimination and fear of Sodium pentobarbital injections (dog). American Psychologist, 1953, 8, 390.

Lyon, D. O. Frequency of reinforcement as a parameter of conditioned suppression. Journal of the Experimental Analysis of Behavior, 1963, 6, 95-98. 
Lyon, D. O. Some notes on conditioned suppression and reinforcement schedules. Journal of the Experimental Analysis of Behavior, $1964,7,289-291$.

Lyon, D. O. A note on response rate and conditional suppression. Psychological Record, 1965, 15, 441, 444.

Lyon, D. O., \& Felton, M. Conditioned suppression and fixed ratio schedules of reinforcement. Psychological Record, 1966, 16, $433-440$.

Lyon, D. O. Conditioned suppression: Operant variables and aversive control. The Psychological Record, 1968, 18, 317-338.

Maher, B. A. Principles of psychopathology. New York: McGraw-Hill, 1966.

Mason, J. W., Brady, J. V., \& Sidman, M. Plasma 17-hydroxycortocasterois levels and conditioned behavior in the rhesus monkey. Endocrinology, 1957, 60, 741-752.

Millenson, J., \& Hendry, D. P. Quantification of response suppression in conditioned anxiety training. Canadian Journal of Psychology, $1967,21,242-251$.

Notterman, J. M., \& Morton, T. M. Notes on related behavioral and physiological indices of stress. Psychological Reports, 1958, 4, 649650 .

Parrish, J. Classical discrimination conditioning of heart-rate and bar press suppression in the rat. Psychonomic Science, 1967, 9, $267-268$.

Patten, R. L., \& Deaux, E. B. Classical conditioning and extinction of the licking response in rats. Psychonomic Science, 1966, 4, $21-22$.

Patten, R. L., \& Rudy, J. W. Orienting during classical conditioning: Acquired verses unconditioned responding. Psychonomic Science, $1967 a$, 7, 27-28.

Patten, R. L., \& Rudy, J. W. The Sheffield omission training procedure applied to the conditioning of the lick response in rats. Psychonomic Science, 1967b, 8, 463-464.

Ray, 0. S., \& Stein, L. Generalization of conditioned suppression. Journal of the Experimental Analysis of Behavior, 1959, 2, 357-361.

Sidman, M., Ray, B. A., Sidman, R. L., \& Klinger, J. M. Hearing and vision in neurological mutant mice: A method of evaluation. Experimental Neurology, 1966, 16, 377-402. 
Singh, S. D. Conditioned emotional response in the rat: I. Constitutional and situational determinants. Journal of Comparative and Physiological Psychology, 1959, 52, 574-578.

Stebbins, W. C., \& Smith, O. A. Cardiovascular concommitants of the conditioned emotional response in the monkey. Science, 1964, 144, 881-883.

Stein, L., Sidman, M., \& Brady, J. V. Some effects of two temporal variables on conditioned suppression. Journal of the Experimental Analysis of Behavior, 1958, 1, 153-162.

Tighe, T. J., Graves, D. M., \& Riley, C. A. Successive reversals of a classically conditioned heart-rate discrimination. Journal of the Experimental Analysis of Behavior, 1968, 11, 199-206.

Valenstein, E. S. The effect of reserpine on the conditioned emotional response in the guinea pig. Journal of the Experimental Analysis of Behavior, $1959,2,219-225$.

Wagner, A. R., Siegel, L. S., \& Fern, G. G. Extinction of conditioned fear as a function of percentage reinforcement. Journal of Comparative and Physiological Psychology, 1967, 63, 160-164.

Watson, J. B., \& Rayner, R. Conditioned emotional reactions. Journal of Experimental Psychology, 1920, 3, 1-14.

Weisman, R. G. Experimental comparison of classical and instrumental appetitive conditioning. American Journal of Psychology, 1965, 78, 423-431.

Willis, R. D., \& Lundin, R. W. Conditioned suppression in the rat as a function of shock reinforcement schedule. Psychonomic Science, $1966,6,107-108$.

Winograd, E. Maintained generalization testing of conditioned suppression. Journal of the Experimental Analysis of Behavior, 1965, $8,47-51$.

Yashida, T., Kai, M., \& Imada, H. A methodological study of CER in rats with "licking" as the criterion response. Japanese Psychological Research, 1969, 11, 66-75. 